\title{
A glacial systems model configured for large ensemble analysis of Antarctic deglaciation
}

\author{
R. Briggs ${ }^{1, *}$, D. Pollard ${ }^{2}$, and L. Tarasov ${ }^{1}$ \\ ${ }^{1}$ Department of Physics and Physical Oceanography, Memorial University of Newfoundland, St. John's, NL, A1B 3X7, \\ Canada \\ ${ }^{2}$ Earth and Environmental Systems Institute, Pennsylvania State University, University Park, PA, USA \\ *now at: C-CORE, St. John's, NL, A1B 3X5, Canada \\ Correspondence to: L. Tarasov (lev@mun.ca)
}

Received: 5 March 2013 - Published in The Cryosphere Discuss.: 11 April 2013

Revised: 1 November 2013 - Accepted: 8 November 2013 - Published: 19 December 2013

\begin{abstract}
This article describes the Memorial University of Newfoundland/Penn State University (MUN/PSU) glacial systems model (GSM) that has been developed specifically for large-ensemble data-constrained analysis of past Antarctic Ice Sheet evolution. Our approach emphasizes the introduction of a large set of model parameters to explicitly account for the uncertainties inherent in the modelling of such a complex system.

At the core of the GSM is a 3-D thermo-mechanically coupled ice sheet model that solves both the shallow ice and shallow shelf approximations. This enables the different stress regimes of ice sheet, ice shelves, and ice streams to be represented. The grounding line is modelled through an analytical sub-grid flux parameterization. To this dynamical core the following have been added: a heavily parameterized basal drag component; a visco-elastic isostatic adjustment solver; a diverse set of climate forcings (to remove any reliance on any single method); tidewater and ice shelf calving functionality; and a new physically motivated, empirically-derived sub-iceshelf melt (SSM) component. To assess the accuracy of the latter, we compare predicted SSM values against a compilation of published observations. Within parametric and observational uncertainties, computed SSM for the present-day ice sheet is in accord with observations for all but the Filchner ice shelf.

The GSM has 31 ensemble parameters that are varied to account (in part) for the uncertainty in the ice physics, the climate forcing, and the ice-ocean interaction. We document the parameters and parametric sensitivity of the model to motivate the choice of ensemble parameters in a quest to approximately bound reality (within the limits of 31 parameters).
\end{abstract}

\section{Introduction}

The Antarctic Ice Sheet (AIS) (for abbreviations see Table 1) is identified as one of the major sources of uncertainty in predicting global sea level change (Meehl et al., 2007). The range of temporal responses to external forcing (e.g. climate, sea level change) is diverse: locally it can be on the order of decades if not less, whereas vast areas of the interior respond over $10^{3} \rightarrow 10^{4}$ yr (Alley and Whillans, 1984; Bamber et al., 2007). Without properly attributing the extent to which the behaviour of the glacial system is an artefact of past climate versus an ongoing response to the present climate, the scientific community will struggle to accurately predict how the AIS will respond to future climatic change and what the contribution to eustatic sea level might be (Huybrechts, 2004; Bentley, 2010). Such attribution faces inherent limitations in models and available observational data. As such, there is an urgent requirement for quantitatively evaluated reconstructions with associated uncertainty estimates.

Ice sheet models, like other numerical models, suffer limitations from simplified or missing physics (e.g. reduced equations due to computational restrictions or poorly understood processes that have no physical law), boundary condition uncertainties, and inherent numerical modelling approximations. Parameterizations offer a way to address these issues (even the simplest models may hide many implicit parameters). Many parameters employed in the model have a range of possible values that can produce plausible output. Exploration of these parameter ranges can be performed to generate an ensemble of results; as such we term them ensemble parameters. The interaction of ensemble parameters, 
Table 1. Table of abbreviations.

\begin{tabular}{ll}
\hline AIS & Antarctic Ice Sheet \\
ACZ & Accumulation zone \\
AMY & Amery Ice Shelf \\
EAIS & East Antarctic Ice Sheet \\
EOF & Empirical orthogonal function \\
EXT & Past ice extent (constraint data type) \\
FIL & Filchner Ice Shelf \\
GHF & Geothermal heat flux \\
GSM & Glacial systems model \\
LGM & Last Glacial Maximum \\
MUN & Memorial University of Newfoundland \\
PD & Present day \\
PDD & Positive degree day \\
PSU & Pennsylvania State University \\
RON & Ronne Ice Shelf \\
ROS & Ross Ice Shelf \\
ROSgl & Ross ice shelf grounding line position \\
RSL & Relative sea level \\
SFZ & Shelf front zone (for SFZ) \\
SIA & Shallow ice approximation \\
SSA & Shallow shelf approximation \\
SSM & Sub-ice-shelf melt \\
WAIS & West Antarctic Ice Sheet \\
volg & Grounded ice volume for all the AIS \\
vol0g & Grounded ice volume at present day $(0 \mathrm{ka})$ \\
vol20g & Grounded ice volume at 20 ka \\
vol0ge & Grounded ice volume for the EAIS \\
vol0gw & Grounded ice volume for the WAIS \\
mESL & (metres) Equivalent sea level \\
ka & $1 \times 10^{3}$ yr before present, i.e. marking the \\
& time of a past event \\
kyr & a period of time lasting $1 \times 10^{3}$ yr \\
\hline &
\end{tabular}

considered together, creates a phase space of possible reconstructions. More complex models invariably have more parameterizations and a larger phase space.

With a handful of ensemble parameters, the traditional method of hand-tuning models with a small number of runs $(\mathcal{O}(10))$ is restrictive and limits exploration of the parameter space. Depending on the non-linearity of the system and the number of parameters, even the generation of relatively large ensembles $\left(\mathcal{O}\left(10^{3}-10^{4}\right)\right)$ is likely far from adequate. As well, with such large numbers of model runs, an objective and systematic means to quantify run quality is critical.

The plausibility of each model run can be assessed by comparisons against observations. Thus, each run can be evaluated in relation to its misfit to the observational data, and a "misfit score" can be attributed allowing runs to be ranked. Runs can then be combined (for example as weighted averages, using the scores as weights) to produce composite deglaciation chronologies. In addition, by capturing the observational, parametric, and structural uncertainties and propagating them into the evaluation process, the cumulative uncertainties can be computed and presented along with the reconstructions (Briggs and Tarasov, 2013). This developing approach has already been applied to other major Quaternary ice sheets (Tarasov and Peltier, 2003, 2004; Tarasov et al., 2012).

This model description and sensitivity assessment paper is one in a suite of three articles documenting the steps undertaken to produce a data-constrained deglaciation chronology, with associated uncertainties, for the AIS using a large ensemble analysis approach (3000 or more runs per ensemble). The second article presents a database of observational data and describes a method that can be employed to quantitatively evaluate model output using the constraint data (Briggs and Tarasov, 2013). The generation of the ensemble and subsequent analysis of the generated chronologies is described in Briggs et al. (in preparation).

The Memorial University of Newfoundland/Penn State University (MUN/PSU) model has been developed specifically for ensemble analysis of AIS deglaciation. The dynamical core of MUN/PSU is based on the Penn State University 3-D ice sheet model (Pollard and DeConto, 2007; Pollard and DeConto, 2009; Pollard and DeConto, 2012b). In this paper we document how MUN/PSU differs from the PSU model and describe 31 ensemble parameters used to explore a set of uncertainties in the glacial systems model (GSM). We also assess model sensitivity to parameter variations.

\section{Model description and spin-up}

The ice dynamical core of the MUN/PSU model is the PSU 3-D ice sheet model (Pollard and DeConto, 2012b, and references therein). The original PSU model was developed for continental scale applications over long (up to $\mathcal{O}\left(10^{6}\right)$ yr) periods. It has been used in many studies for the AIS and other ice sheets (see Pollard and DeConto, 2012b, for a complete list) over a range of spatial and temporal scales and has generally performed well within the range of other models in the ISMIP-HEINO, ISMIP-HOM, and MISMIP intercomparison tests (Calov et al., 2010; Pattyn et al., 2008, 2012).

The key features of the MUN/PSU GSM are (items marked with an asterisk deviate significantly from the PSU model) the following:

- treatment of both shallow ice and shallow shelf/stream regimes, including a parameterization based on Schoof (2007) boundary layer theory

- a standard coupled thermodynamic solver including horizontal advection, vertical diffusion and heat generated from deformation work

- * parameterized basal drag coefficient that accounts for sub-grid topographic roughness, sediment likelihood (based on some specific assumptions), and systematic model-to-observation ice thickness misfit 
- *visco-elastic isostatic adjustment (bedrock response to surface loading) component

- * parameterized climate forcing that generates three separate temperature and precipitation fields concurrently, which are subsequently merged, through further ensemble parameters, to produce a final "blended" set of climate fields (developed to avoid dependence on a single climate forcing parameterization)

- * parameterizations for the separate treatment of tidewater and ice shelf front calving

- *a new physically motivated empirical approach to sub-ice-shelf melt (SSM)

We expose underlying GSM uncertainties (inevitably to an incomplete extent) through a synthesis of previous parameterizations from the literature with a focus on making explicit at least some of the underlying parametric sensitivities. Their validation stems from a combination of the documented source origin, physical plausibility/motivation, and resultant impact on characteristics/statistics of generated ice sheet chronologies.

The 31 ensemble parameters in the GSM are summarized in Table 2. They are listed in the order they are discussed in the text and organized in accordance with the model functionality they affect: ice dynamics (10 parameters), climate forcing (12 parameters) and ice-ocean mass loss through calving and sub-ice-shelf melt (9 parameters). The evolution of the parameter range and justifications for choosing/excluding parameters are discussed in greater detail in Sect. 3. The ranges presented in Table 2 contains three values, the upper bound, the value of the parameter from a baseline run, and the lower bound. The baseline run is used and discussed fully in the sensitivity assessment (Sect. 3). The baseline run has one of the smallest misfit-to-observation scores of runs to date as identified through the application of the constraint data and the evaluation scheme (Briggs and Tarasov, 2013). Table 3 provides a full list of all the variables and non-ensemble parameters discussed in the text.

\subsection{Model setup}

We adopt the same discretization methodology as the PSU model (Pollard and DeConto, 2009, 2012b). In summary, for the context of our large ensemble-based analysis, the MUN/PSU model is run at a resolution of $40 \mathrm{~km}$ in the horizontal direction and uses a finite-difference Arakawa-C grid. In the vertical the grid has 10 uneven layers, spaced closer at the surface and base of the ice. The horizontal velocities $u, v$ are located between the grid points (i.e. staggered half a grid cell), whereas the ice geometry (e.g. ice thickness $H$, surface elevation $h_{\mathrm{s}}$ ), vertical velocities, and temperatures are located at the grid centres. A comparison of results for the PSU model at 40, 20 and $10 \mathrm{~km}$ resolutions are shown in Fig. 6 of Pollard and DeConto (2012b) and Appendix C of
Pollard and DeConto (2012a), with very little difference in computed modern ice distributions. The primary model feature that allows this insensitivity to resolution is the grounding line flux parameterization of Schoof (2007), as discussed in the above two references.

The standard model run is from $205 \mathrm{ka}$ to present day (the initialization conditions are described in Sect. 2.11). The model has adaptive time-stepping functionality that, if numerical instabilities occur, enables the GSM to revert to a previous state (the state is recorded by a rolling buffer) and re-attempt the calculations with reduced time steps (50\% reduction upon each reversion). After $300 \mathrm{yr}$ under reduced time step conditions, the time step is doubled. On initialization the ice dynamics are set to be computed every $0.5 \mathrm{yr}$, thermodynamics every $10 \mathrm{yr}$, and isostatic adjustment every $100 \mathrm{yr}$.

\subsection{Ice dynamics}

Grounded and floating ice have the same fundamental rheology, but the large-scale (simplified) equations that describe them are different. Three regimes classify the type of ice flow: sheet flow, stream flow and shelf flow. Sheet flow, under the zero-order shallow-ice approximation (SIA), is valid for an ice mass with a small aspect ratio (height scale $\ll$ length scale) and where the flow is dominated by vertical shear stress, i.e. much of the interior of the AIS. It is the simplest type of flow. The driving stress is in balance with basal traction (the retaining force due to friction at the interface between an ice sheet and the underlying bed). The flow is dominated by vertical shear $(\partial u / \partial z$, where $u$ is velocity and $z$ is the vertical co-ordinate within the ice thickness) determined locally by the driving stress. The driving stress is a function of the surface gradient and the thickness; steeper slopes and/or thicker ice beget larger driving stresses. In shallow shelf flow (SSA), the driving stress is balanced by longitudinal and transverse (horizontal) shear stress gradients. Stream flow is similar to shelf flow, except for the presence of basal drag, and the basal topographic boundary condition (MacAyeal, 1997).

The PSU model offers three approaches to modelling these three different regimes. Computationally, the most costly implements a combined set of SIA-SSA equations over the whole ice sheet. The internal shear and longitudinal stretching is combined, through strain-softening terms that are velocity dependent, into one set, which is applied at all locations. As a consequence, the viscosity is a function of the velocity gradients. Thus the set of equations is non-linear in the velocity terms, as well as dependent on the state of the ice (e.g. ice thickness, temperatures, etc.). To address the non-linearity, an iterative approach is taken, whereby the viscosity term is computed based on the previously calculated velocity. The new viscosity term is then used to update the velocities. This is repeated until the difference between the velocities is less than a predetermined convergence criterion 
Table 2. Ensemble parameters. $\mathrm{LB}=$ lower bound, $\mathrm{BA}=$ baseline and $\mathrm{UB}=$ upper bound. Values are rounded to 2 decimal places.

\begin{tabular}{|c|c|c|c|c|c|}
\hline & Definition & Parameter & F90 code name & $\begin{array}{l}\text { Range } \\
\mathrm{LB}[\mathrm{BA}] \mathrm{UB}\end{array}$ & Units \\
\hline \multicolumn{6}{|c|}{ Ice dynamics } \\
\hline 2 & Flow enhancement coef. for shelf flow & shelfflowC & fnshelf & $0.40[0.57] 0.65$ & \\
\hline 3 & Hard bed basal sliding coef. & slidhardC & fnslid & $\begin{array}{l}1 \times 10^{-10}\left[2.57 \times 10^{-9}\right] \\
1 \times 10^{-8}\end{array}$ & $\mathrm{myr}^{-1} \mathrm{~Pa}^{-2}$ \\
\hline 5 & $\begin{array}{l}\text { Sediment presence coefficient after isostatic } \\
\text { unloading }\end{array}$ & sedpresC & $1-$ fhbkPhif & $0.001[0.81] 1.0$ & \\
\hline 6 & Model-obs ice thickness misfit scaling & HmisfitS & $\begin{array}{l}1.6 \times \\
\log (\text { fDragmod })\end{array}$ & $1.00[7.2] 11$ & \\
\hline \multicolumn{6}{|c|}{ Climate forcing } \\
\hline 11 & $\begin{array}{l}\text { Radiative or glacial index response coef. for } \\
\text { temperature }\end{array}$ & TresponseC & fnTdfscale & $0.75[1.19] 1.30$ & \\
\hline 12 & Temperature lapse rate & Tlapse & rlapseR & $5.00[8.31] 11.00$ & ${ }^{\circ} \mathrm{Ckm}^{-1}$ \\
\hline 13 & LGM temperature EOF field ( $\mathrm{Tf}_{3}$ only) & TeofC & fTeof & $-0.50[-0.44] 0.50$ & \\
\hline 14 & Temperature mixing 1 & Tmix1 & Twa & $0.00[0.46] 1.00$ & \\
\hline 15 & Temperature mixing 2 & Tmix2 & Twb & $0.00[0.03] 1.00$ & \\
\hline 16 & Phase exponent for precipitation & PphaseEXP & fnPdexp & $0.50[1.94] 2.00$ & \\
\hline 17 & LGM precipitation EOF fields ( $\mathrm{Pf}_{3}$ only) & Peof1C & fPeof1 & $-0.50[0.16] 0.50$ & \\
\hline 18 & LGM precipitation EOF fields $\left(\mathrm{Pf}_{3}\right.$ only) & Peof 2C & fPeof 2 & $-0.50[-0.44] 0.50$ & \\
\hline 24 & Ice shelf calving minimum thickness threshold & Hshelfcrit & Hcrit2 & $10.00[89.5] 150.00$ & $\mathrm{myr}^{-1}$ \\
\hline 25 & $\begin{array}{l}\text { Ice shelf calving sub-Hshelfcrit enhancement } \\
\text { coef. }\end{array}$ & shelfcalv2C & calvF & $0.00[0.08] 0.20$ & $\mathrm{yr}^{-1}$ \\
\hline 26 & Maximum calving velocity, tidewater glacier & calvmaxV & $10 \cdot$ fcalvVmx & $0.10[7.9] 10.00$ & $\mathrm{kmyr}^{-1}$ \\
\hline 27 & Thin ice calving temperature-dependent coef. & calvthinC & fcalvwater & $3.00[7.92] 10.00$ & $\mathrm{myr}^{-1}$ \\
\hline 28 & Grounding line zone SSM coef. (large shelves) & SSMGLz1C & fnGLz1 & $0.50[1.51] 2.50$ & $\mathrm{myr}^{-1}$ \\
\hline 29 & Grounding line zone SSM coef. (other shelves) & SSMGLz2C & fnGLz2 & $0.50[1.56] 3.00$ & $\mathrm{myr}^{-1}$ \\
\hline 30 & Shelf front SSM coef. (large shelves) & SSMfrontC & fnSfz1 & $0.50[1.70] 2.50$ & $\mathrm{myr}^{-1}$ \\
\hline 31 & Shelf front melt climate-dependence coef. & SSMfrontTC & fnzclimsfz & $0.00[0.65] 1.18$ & \\
\hline
\end{tabular}

(Pollard and DeConto, 2007, 2012b). Significant savings in CPU time, with virtually no impact on the results, can be earned by limiting the combined SIA-SSA equations to cells where SSA flow is predisposed to dominate due to low basal drag; above a critical threshold (satisfied in the majority of the East Antarctic Ice Sheet (EAIS)) the flow is limited to SIA (Pollard and DeConto, 2009). Further reductions in computing resource can be achieved by removing the SIA strain- softening terms from the SSA equations (however both SIA and SSA are still iteratively computed). This has a slight impact on the results (Pollard and DeConto, 2012b). The removal of these strain-softening terms will generally tend to slightly increase the height-to-width (aspect) ratio of the ice, which to a certain extent is compensated for by the ensemble parameter flow law coefficient. Because the large ensemble approach is computationally costly (each ensemble contains 
Table 3. Table of symbols and (non-ensemble) model parameters discussed in the text.

\begin{tabular}{|c|c|c|c|}
\hline Symbol & Definition & Units & Value \\
\hline calvrate $_{\mathrm{Ts}}$ & Ice shelf calving rate & $\mathrm{myr}^{-1}$ & \\
\hline crh & Basal sliding coefficient (between bed and ice) & $\mathrm{myr}^{-1} \mathrm{~Pa}^{-2}$ & \\
\hline crhcrit & SSA-SIA critical threshold & $\mathrm{myr}^{-1} \mathrm{~Pa}^{-2}$ & $10^{-10}$ \\
\hline$\dot{C}$ & Calving rate & $\mathrm{myr}^{-1}$ & \\
\hline$H$ & Ice thickness & $\mathrm{m}$ & \\
\hline$H_{\text {flot }}$ & Maximum buoyant thickness for tidewater calving & $\mathrm{m}$ & \\
\hline $\mathrm{hb}$ & Basal elevation, relative to present-day sea level & $\mathrm{m}$ & \\
\hline$h_{\mathrm{S}}$ & Surface elevation & $\mathrm{m}$ & \\
\hline$h_{\mathrm{SPD}}$ & Reference present-day ice surface elevation & $\mathrm{m}$ & \\
\hline$I$ & Glacial index, derived from either $T_{\text {epica }}$ & & \\
\hline$n_{\text {edge }}$ & No. grid cell edges that meet tidewater conditions & (see Sect. 2.10.1) & \\
\hline$\dot{\mathrm{M} g}$ & Sub-ice-shelf melt (SSM) rate for grounding line zone & $\mathrm{myr}^{-1}$ & \\
\hline$\dot{\mathrm{Mg}} \mathrm{g}_{\mathrm{AMY}}$ & Reference SSM rate for AMY grounding line zone & $\mathrm{myr}^{-1}$ & \\
\hline$\dot{\mathrm{Mg}} \mathrm{RON}$ & Reference SSM rate for RON grounding line zone & $\mathrm{myr}^{-1}$ & \\
\hline$\dot{\mathrm{Ma}}$ & SSM rate for accretion zone & $\mathrm{myr}^{-1}$ & \\
\hline$\dot{\mathrm{M} s}$ & SSM rate for shelf front zone & $\mathrm{myr}^{-1}$ & \\
\hline$P$ & Interpolated (blended) precipitation & $\mathrm{myr}^{-1}$ & \\
\hline$P_{\text {LGM }}$ & Reference LGM precipitation field & $\mathrm{myr}^{-1}$ & \\
\hline$P_{\mathrm{PD}}$ & Reference PD precipitation field & $\mathrm{myr}^{-1}$ & \\
\hline Pave $_{\text {LGM }}$ & PMIP II average LGM precipitation field & $\mathrm{myr}^{-1}$ & \\
\hline Peof1,2LGM & PMIP II reference LGM precipitation EOFs & $\mathrm{myr}^{-1}$ & \\
\hline $\mathrm{Pf}_{1,2,3}$ & Individual precipitation fields & $\mathrm{myr}^{-1}$ & \\
\hline Pfac & Scaled precipitation glacial index & & \\
\hline $\mathrm{Se}$ & Sediment presence exponent & & \\
\hline Slk & Sediment likelihood parameter & & \\
\hline$t$ & Time & $\mathrm{yr}$ & \\
\hline$T$ & Interpolated (blended) temperature & ${ }^{\circ} \mathrm{C}$ & \\
\hline$T_{\mathrm{S}}$ & Sea surface mean summer temperature & ${ }^{\circ} \mathrm{C}$ & \\
\hline$T_{\mathrm{LGM}}$ & Reference LGM temperature field & ${ }^{\circ} \mathrm{C}$ & \\
\hline$T_{\mathrm{PD}}$ & Reference PD temperature field & ${ }^{\circ} \mathrm{C}$ & \\
\hline Tave $_{\text {LGM }}$ & PMIP II averaged LGM temperature & ${ }^{\circ} \mathrm{C}$ & \\
\hline Teof $_{\text {LGM }}$ & PMIP II LGM temperature EOFs & ${ }^{\circ} \mathrm{C}$ & \\
\hline $\mathrm{Tf}_{1,2,3}$ & Individual temperature fields & ${ }^{\circ} \mathrm{C}$ & \\
\hline$T_{\mathrm{Cmn}}$ & Minimum critical $T_{\mathrm{S}}$ for tidewater calving & ${ }^{\circ} \mathrm{C}$ & -5 \\
\hline$T_{\mathrm{Cmx}}$ & Maximum critical $T_{\mathrm{S}}$ for tidewater calving & ${ }^{\circ} \mathrm{C}$ & 2 \\
\hline$u, v$ & Total horizontal velocities & $\mathrm{ms}^{-1}$ & \\
\hline$u_{\mathrm{b}}, v_{\mathrm{b}}$ & Horizontal basal velocities & $\mathrm{m} \mathrm{s}^{-1}$ & \\
\hline$U_{\mathrm{c}}$ & Tidewater calving velocity & $\mathrm{km} \mathrm{yr}^{-1}$ & \\
\hline$U_{\mathrm{Cmx}}$ & Maximum calving velocity & $\mathrm{km} \mathrm{yr}^{-1}$ & \\
\hline crhMN & Minimum basal sliding coefficient & $\mathrm{m} \mathrm{yr}^{-1} \mathrm{~Pa}^{-2}$ & $5 \times 10^{-11}$ \\
\hline $\operatorname{crhMX}$ & Maximum basal sliding coefficient & $\mathrm{m} \mathrm{yr}^{-1} \mathrm{~Pa}^{-2}$ & $6 \times 10^{-5}$ \\
\hline$\Delta H_{\mathrm{alb}}$ & Model -obs ice thickness misfit & $\mathrm{km}$ & \\
\hline$\Delta s$ & $\delta^{18} \mathrm{O}$ sea level departure from present & & \\
\hline$\Delta q_{\mathrm{s}}$ & Annual orbital insolation anomaly from present day at $80^{\circ} \mathrm{S}$ & $\mathrm{W} \mathrm{m}^{-2}$ & \\
\hline$\epsilon_{\text {shf }}$ & Shelf aspect ratio & & \\
\hline$\epsilon_{\mathrm{AMY}}$ & AMY shelf aspect ratio & & \\
\hline$\epsilon_{\mathrm{RON}}$ & RON shelf aspect ratio & & \\
\hline$\sigma_{\mathrm{hb}}$ & Bed roughness & $10 \times \mathrm{m}$ & \\
\hline$\tau_{\mathrm{b}}$ & Basal stress & $\mathrm{Pa}$ & \\
\hline$|\phi|$ & Latitude & ${ }^{\circ}$ south & \\
\hline
\end{tabular}


order 3000 runs; each run can take 2-5 days on a single processor core), the latter method is employed for this study.

\subsection{Ice rheology factor}

The sheet and shelf flow enhancement ensemble parameters, flow $\mathbf{C}$ and shelfflow $\mathbf{C}^{1}$, multiplicatively adjust the ice rheology (Pollard and DeConto, 2012b, Eqs. 16a and 16b). They are motivated as providing softening due to the unresolved grain-scale characteristics (e.g. ice crystal size, orientation, impurities) of the ice (Cuffey and Paterson, 2010, p. 71). Enhancement factors are between 3.5 and 5.5 for sheet flow and between 0.4 and 0.65 for shelf flow. This approximately follows the bounds defined in Ma et al. (2010). Physically they manifest themselves as a control on the height-to-width ratio of the ice sheet (Huybrechts, 1991).

\subsection{Basal drag}

Though a consensus is developing towards the validity of Coulomb plastic basal drag from subglacial sediment deformation (Cuffey and Paterson, 2010), the Schoof grounding line flux condition (Schoof, 2007) is only defined for power law forms. We therefore retain the warm-based basal drag parameterization of Pollard and DeConto (2007, 2012b),

$u_{\mathrm{b}}=\mathrm{crh} \cdot \tau_{\mathrm{b}}^{2}$,

where $u_{\mathrm{b}}$ is the basal sliding velocity, crh is the basal sliding coefficient, and $\tau_{\mathrm{b}}$ is the basal stress. The basal drag parameterization is written in an inverted basal sliding form to provide a conceptually simpler linear relationship between crh and basal velocity. Once the non-linearity of the ice system is factored in, the proportionality will, however, cease to be linear. Runs with ensemble parameters that generate larger values of crh will generally have increased basal velocities, but this is unlikely to hold everywhere at every time. A future study will examine model sensitivity to the form of basal drag law (i.e. including the value of the exponent, replacement with a Coulomb plastic relationship, and inclusion of full coupling with basal hydrology).

To capture the large uncertainty in subglacial basal stress regimes, we have introduced a number of ensemble parameters that are used to determine the basal sliding coefficient.

Firstly, following Pollard and DeConto (2012b), we consider the local bed to be either hard or soft (sediment) bed dominated. These two regimes have corresponding ensemble parameters: slidhardC $\left(1 \times 10^{-10}\right.$ to $1 \times 10^{-8} \mathrm{~m} \mathrm{yr}^{-1} \mathrm{~Pa}^{-2}$, predominantly under the EAIS) and slidsedC $\left(5 \times 10^{-7}\right.$ to $3 \times 10^{-5} \mathrm{~m} \mathrm{yr}^{-1} \mathrm{~Pa}^{-2}$, predominantly under the WAIS).

The parameterization has three key dependencies. First, as per Pollard and DeConto (2012b), we assume that the distribution of subglacial sediment is largely related to the surface elevation of the unloaded subglacial topography. Areas

\footnotetext{
${ }^{1}$ All ensemble parameter names are boldfaced.
}

that are still submerged after glacial unloading are likely to have soft sedimentary surface lithology, and therefore are a precursor for subglacial sediment. With some allowance for uncertainty in the resultant unloaded surface elevation (dependent on present-day ground surface elevation and ice thickness, and thus uncertainty in ALBMAP(LeBrocq et al., 2010), earth rheology, subglacial erosion rates, etc.) under the control of a parameter sedpresC (0.001-1), we define a sediment likelihood parameter

$$
\text { Slk }=\frac{\text { unloaded water depth in } \mathrm{km}}{\text { sedpresC }} .
$$

The sedpresC parameter can arguably be interpreted as an allowance for an uncertain amount of erosion since initial glaciation that would otherwise bias the inference of longterm marine submergence prior to glacial loading. We use Slk to set a sediment presence exponent, Se, that controls the transition from slidhardC to slidsedC (bare rock to sediment):

$$
\mathrm{Se}=\left\{\begin{array}{l}
1, \text { if Slk }>1 \quad \text { unloaded marine: thick sediment cover } \\
\text { Slk, if } 0 \leq \mathrm{Slk} \leq 1 \quad \text { some sediment } \\
0, \text { if } \mathrm{Slk}<0 \quad \text { unloaded terrestrial: no sediment. }
\end{array}\right.
$$

The second dependence is on sub-grid roughness, given by the standard deviation ( $\sigma_{\mathrm{hb}}$, in dekametres) of the $5 \mathrm{~km}$ resolution ALBMAP (LeBrocq et al., 2010) ${ }^{2}$ basal topography for each GSM grid cell. For Antarctic and associated ice shelves, $\sigma_{\mathrm{hb}}$ ranges from 0.16 to 2.4 with an unweighted mean value of 0.80 . For regions with thick sediment cover $(\mathrm{Se}>0.67)$, we assume that higher roughness will lead to increased basal drag. For minimal or no sediment cover $(\mathrm{Se}<0.5)$, we assume that enhanced surface roughness increases the surface area available to erosion, promoting trapping of eroded sediments, leading to reduced basal drag. For consistency of the above logic, any site with sediment cover should have reduced basal drag compared to sites without sediment cover. Below we detail one way to enforce this consistency, but it is not implemented in the results presented herein.

The final dependence takes into account the local ice thickness difference $\Delta H_{\text {alb }}$ between the present-day field from a best-fitting test run from a previous ensemble and ALBMAP thickness $H_{\mathrm{ALB}}$ (in $\mathrm{km}$ ). Thus we address some observation model misfit in the adjustment of crh and perhaps partially compensate for weaknesses in the assumptions of the

\footnotetext{
${ }^{2}$ The ALBMAP dataset is provided at a resolution of $5 \mathrm{~km}$. To be used in the GSM it must be upscaled to the model resolution of $40 \mathrm{~km}$; the steps taken to upscale the dataset, whilst preserving grounding line positions and key pinning points, are described in the supporting online material (SOM) of Briggs and Tarasov (2013). Unless explicitly stated (as in this case for sub-grid roughness) in the text any references to ALBMAP implicitly refer to the upscaled dataset at $40 \mathrm{~km}$.
} 
first two dependencies. This is a similar, albeit much simpler, approach to the local inverse method employed by Pollard and DeConto (2012a) to adjust the values of crh to reduce model misfit. The HmisfitS (range 0.0-11.0) ensemble parameter scales the exponential sensitivity to $\Delta H_{\mathrm{alb}}$, so that for $\Delta H_{\mathrm{alb}}>0$ (i.e. test run ice thickness in excess of ALBMAP) the parameterization results in a larger value of crh and therefore increased basal velocities and reduced basal drag.

The basal sliding coefficient crh is set as

$$
\begin{aligned}
\operatorname{crh} & =F\left(T_{\mathrm{b}}\right) \cdot \max \left[\operatorname { m i n } \left[\operatorname{slidhardC}\left(\frac{\text { slidsedC }}{\text { slidhardC }}\right)^{\mathrm{Se}}\right.\right. \\
& \left.\left.\cdot \text { fstd } \cdot \exp \left(\left(\text { HmisfitS } \cdot \Delta H_{\mathrm{alb}}\right)\right), \operatorname{crhMX}\right], \operatorname{crhMN}\right],
\end{aligned}
$$

where $F\left(T_{\mathrm{b}}\right)$ nominally denotes the temperature dependence for the cold-to-warm-based transition detailed below. Model parameters crhMX and crhMN set the respective warm-based upper and lower bounds for crh. The bed roughness dependency (fstd) in the above expression for crh is given by

$$
\begin{array}{ll}
\text { if Se }>0.67 \text { then } & \triangleright \text { thicker sediment } \\
\text { if } \sigma_{\mathrm{hb}} \geq 0.75 \text { then } & \triangleright \text { rougher sub-grid topography } \\
\text { fstd }=\max \left[\left(0.75 / \sigma_{\mathrm{hb}}\right)^{\text {sedEXP }}, \Gamma_{\text {bnd }}\right] \triangleright \text { decreased sliding } \\
\text { else } \quad \triangleright \text { smoother sub-grid topography } \\
\text { fstd }=\left(1+\left(0.75-\sigma_{\mathrm{hb}}\right) / 0.69\right)^{\text {sedEXP }} \\
\text { end if } & \triangleright \text { increased sliding } \\
\text { else if } \mathrm{Se}<0.5 \text { then } & \triangleright \text { thinner sediment } \\
\text { fstd }=\min \left[\sigma_{\mathrm{hb}}^{\text {slidEXP }}, \Gamma_{b n d}\right] & \triangleright \text { sliding increased for } \\
\text { else } & \text { rough topography } \\
\text { fstd }=1 & \\
\text { end if. } &
\end{array}
$$

For the results presented below, $\Gamma_{\text {bnd }}$ is inactive (e.g. set to 0 for $\sigma_{\mathrm{hb}} \geq 0.75$ and $10^{5}$ otherwise). To enforce that fstd never induces overlap of crh values between hard ( $\mathrm{Se}<$ $0.5)$ and soft bed $(\mathrm{Se} \geq 0.5)$ ranges, one choice is that which sets crh to the geometric mean of slidsedC and slidhardC $\left(\Gamma_{\text {bnd }}=(\text { slidsedC/slidhardC })^{(0.5-S e)}\right)$. However, other choices are also plausible, and one could therefore argue for the introduction of another ensemble parameter to set the value of $\Gamma_{\text {bnd }}$. Future work will use a high-resolution, higher-order ice sheet model to develop a better constrained accounting of the impact of sub-grid topography on ice flow and basal motion for continental-scale glacial-cycle modelling where mountain resolving resolution is not feasible.

High sub-grid topographic roughness is also likely to entail significant sub-grid variation in basal temperature relative to the pressure melting point. Our sliding coefficient parameterization above is inactive for regions that are coldbased, and therefore the effective basal drag may be overestimated in these regions. Pollard and DeConto (2012b) parameterized an allowance for this effect that will be consid- ered for future model upgrades (again after a high-resolution model comparison).

As shown in Supplement Fig. 1, ensemble parameters HmisfitS, slidEXP, sedEXP, slidhardC and slidsedC permit a wide range of basal sliding coefficients in response to variations in $\Delta H_{\text {alb }}$ and $\sigma_{a l b}$. Aside from the above-described dependencies and the constraints of appropriate scale response (which motivated some of the power terms) and numerical continuity, the exact form of the above drag coefficient equations developed in a somewhat ad hoc trial-anderror approach. For instance, the values in the second fstd relationship above (i.e. for $\mathrm{Se}>0.67$ and $\mathrm{Se}<0.75$ ) were constrained by continuity and a decision to make the maximum value of fstd $=2^{\text {sedEXP }}$. For the case of the slidEXP and $\operatorname{sedEXP}=1$, the above equation gives fstd a range of [0.167-2] for $\mathrm{Se}>0.67$ and [1-4.5] for $\mathrm{Se}<0.5$. The ensemble parameters sedEXP and slidEXP both have ranges of $0: 12$. Numerical coefficients were selected from initial sensitivity analyses while maintaining numerical continuity. An example basal sliding coefficient field is shown in Fig. 1. Values of $\log (\mathrm{crh})$ below -8.59 in the figure are due to the $\exp \left(\left(\right.\right.$ HmisfitS $\left.\left.\cdot \Delta H_{\mathrm{alb}}\right)\right)$ factor in Eq. (4).

It may be that the parameter ranges of slidsedC and slidhardC will turn out to be physically untenable. However, at this stage, we deem errors from inadequate parameter range coverage of more concern. Deleting results with untenable parameter values in the future is much less costly than having missed a sector of the potential parameter space that better corresponds to "reality".

Mass fluxes for grounded ice with basal sliding coefficient $\mathrm{crh}>$ crhcrit $=10^{-8} \mathrm{~m} \mathrm{yr}^{-1} \mathrm{~Pa}^{-2}$ are determined by the combined SSA and SIA equations; otherwise only SIA is active. At the cold-to-warm-based transition, crh smoothly increases in value from an essentially zero $\left(10^{-20} \mathrm{~m} \mathrm{yr}^{-1} \mathrm{~Pa}^{-2}\right)$ value starting at basal temperature $-0.5^{\circ} \mathrm{C}$ below the pressure melting point. The temperature coefficient, $F\left(T_{\mathrm{b}}\right)$, in Eq. (4) implements an exponential transition that reaches a maximum value of one at the pressure melting point, except at the grounding line where a warm base (i.e. $F\left(T_{\mathrm{b}}\right)=1$ ) is always imposed.

\subsection{Grounding line treatment}

At the locality of the grounding line and in ice streams with very little basal traction, a combination of both ice sheet and ice shelf flow regimes exists (Pollard and DeConto, 2007).

The grounding line treatment in the model is based on Schoof (2007), who showed that, to capture the grounding line accurately, either the grounding zone boundary layer must be resolved at a very high resolution $(\sim 0.1 \mathrm{~km}$, impractical on a continental scale except for models with an adaptive grid such as that of Cornford et al., 2013) or an analytical constraint on the flux, $q_{\mathrm{g}}$, across the grounding line must be applied. The flux is a function of the longitudinal stress across the grounding line, the ice thickness 


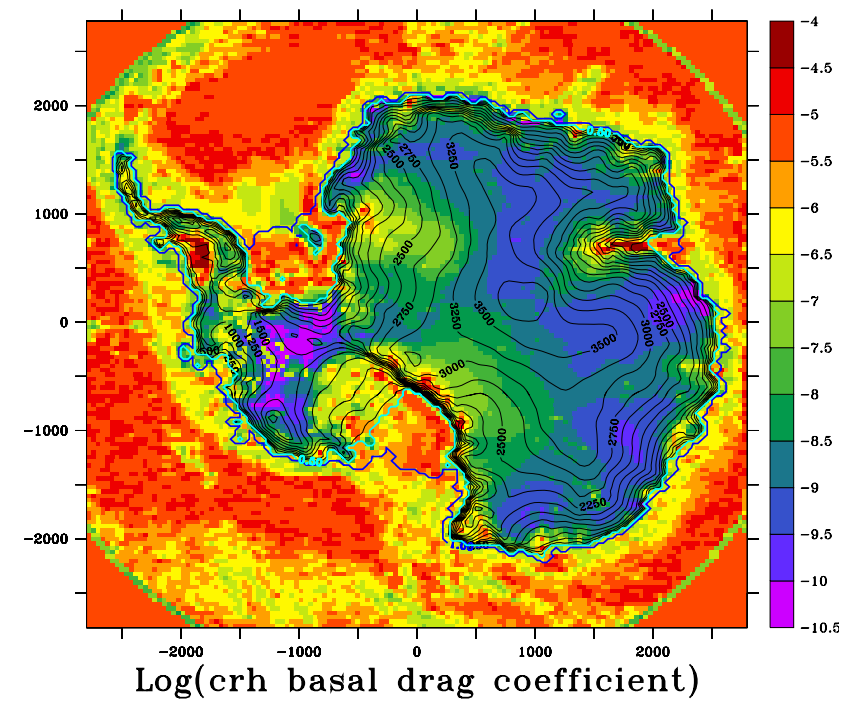

Fig. 1. Basal sliding coefficient for baseline parameter vector nn2679 and associated surface elevation contours. Note value reductions due to cold basal conditions have not been applied to the plotted field. The logarithms of slidhardC and slidsedC have respective values -8.5886 and -5.2881 .

at the grounding line, and the sliding coefficient discussed above (Schoof, 2007). The longitudinal stress is calculated by the stress balance equation and also takes into account back stress at the grounding line caused by buttressing from pinning points, downstream islands or side shear at lateral margins.

The analytically calculated ice flux $q_{\mathrm{g}}$ and height at the grounding line $H_{\mathrm{g}}$, found through linear interpolation, are then used to compute the depth-averaged velocity at the grounding line $u_{\mathrm{g}}=q_{\mathrm{g}} / H_{\mathrm{g}}$. The calculated $u_{\mathrm{g}}$ is imposed as an internal boundary condition for the shelf-flow equations and is used to overwrite the velocity solution calculated for that position from the stress balance equations (Pollard and DeConto, 2007, 2012b).

\subsection{Sub-ice-shelf pinning points}

Pinning points, sometimes manifest in the form of small ice rises, are found below the ice shelves, generally toward the grounding line. Grounding of the ice shelf onto such pinning points causes additional back stresses that influence the migration of the grounding line (Pollard and DeConto, 2012b). These pinning points are too small to be resolved on a $40 \mathrm{~km}$ grid, and the pinning point drag is therefore parameterized to be a fraction of the equivalent basal drag for grounded ice as a function of the water depth. Ensemble parameter pinC (range 0.01-0.1) scales the computed pinning point drag by assuming that the fraction of grounded ice is given by $\max \left[0 ., \min \left(1 ., 1 .-\left(h_{\mathrm{w}} / 300.\right)\right)\right] \times \mathbf{p i n C}$, where $h_{\mathrm{w}}$ is the water depth (m) and coefficients are taken from Pollard and DeConto (2009).

\subsection{Isostatic adjustment and relative sea level computation}

The isostatic adjustment component of the GSM is taken from Tarasov and Peltier (2004) but modified to use the VM5a earth rheology of Peltier and Drummond (2008) which still retains a $90 \mathrm{~km}$-thick elastic lithosphere. The visco-elastic earth rheology is spherically symmetric and has reasonable fits to geophysical observations from North America (Peltier and Drummond, 2008). The bedrock displacement is computed every $100 \mathrm{yr}$ from a space-time convolution of surface load changes and a radial displacement Greens function, at spherical harmonic degree and order 256.

This study considers the glaciological and climatic uncertainties in the GSM, but assessment of the contribution from rheological uncertainties is a future project. For a preliminary examination of the impact of Earth model uncertainty on inferred Antarctica deglacial history see Whitehouse et al. (2012). Variations (within bounds from geophysical constraints) in the earth rheology will have some impact on ice evolution, but that will get swamped by the other uncertainties, e.g. the climate forcing.

\subsection{Geothermal heat flux (GHF)}

There are very few direct measurements of GHF for the AIS. Those that do exist are usually derived from direct temperature measurements in ice cores (Pattyn, 2010). As such, continental scale GHF reconstructions must be derived from proxies. This study employs two GHF datasets which are linearly blended through ensemble parameter GHFmix. The Shapiro and Ritzwoller (2004) dataset uses a global seismic model of the crust and upper mantle to extrapolate available measurements to regions where they are non-existent or sparse. The Fox Maule et al. (2005) dataset was estimated from satellite-measured magnetic data. The GHF field in the model linearly ranges from the former $(\mathbf{G H F m i x}=1)$ to the latter $(\mathbf{G H F m i x}=0)$ dataset. The datasets are corrected, around a Gaussian area of influence, so that the reconstructions match the observations where available (Pattyn, 2010). The observations are derived from ice core temperature profiles and based on the location of sub-glacial lakes (the ice/bedrock interface can then be considered to be at the pressure melting point, and thus the minimum GHF can be computed; Pattyn, 2010).

\subsection{Climate forcing}

Climate forcing over glacial cycles is one of the most difficult components to constrain (Tarasov and Peltier, 2004). In the GSM, 12 of the 31 ensemble parameters adjust the climate forcing. The GSM requires both temperature and precipitation fields. For large ensemble analysis, coupled climateglacial systems models are computationally too expensive; as such the GSM uses a parameterized climate forcing. Three 
different parameterizations, each of which has one or more ensemble parameters, are used to concurrently generate the temperature $\left(\mathrm{Tf}_{1,2,3}\right)$ and precipitation $\left(\mathrm{Pf}_{1,2,3}\right)$ fields.

The spatial distribution of the fields is obtained through empirical parameterizations, from published observational datasets (e.g. Arthern et al., 2006), or for $\mathrm{Tf}_{3}$ from the PaleoModelling Intercomparison Project II (PMIP II; Braconnot et al., 2007) modelling study.

The fields are then projected backwards in time using an ice or deep-sea core time series (Ritz et al., 2001; Huybrechts, 2002; Tarasov and Peltier, 2006; Pollard and DeConto, 2009). Finally, the different fields are combined using a weighed sum, the weight determined by ensemble parameters, to generate the final climate fields that force the GSM.

This approach ensures there is no reliance on a single climate methodology and that each method has one or more ensemble parameters. This affords the model a larger degree of freedom (with respect to climate forcing) than the single climate forcing methodology with limited parameterization employed in other studies (e.g. Pollard and DeConto, 2012b; Whitehouse et al., 2012).

\subsubsection{Temperature forcing}

$\mathrm{Tf}_{1}$ models the spatial variation of the temperature field as a function of latitude, height, and lapse rate with coefficients from Martin et al. (2011) and sea level dependence from Pollard and DeConto (2009). Using the annual orbital insolation anomaly $\left(\Delta q_{\mathrm{s}}\right)$ at $80^{\circ} \mathrm{S}\left(\mathrm{W} \mathrm{m}^{-2}\right)$ and sea level departure from present $(\Delta s)$, the modern-day temperature field is adjusted to generate a palaeo-temperature field. Annual orbital insolation is calculated from Laskar et al. (2004) and, following Tarasov and Peltier (2004), it is weighted by ensemble parameter TresponseC (range 0.75-1.3) to account for the uncertainty inherent in using this method to drive the transition between a glacial and interglacial state. The sea level departure from present is taken from stacked benthic $\delta^{18} \mathrm{O}$ records (Lisiecki, 2005). Present-day $\mathrm{Tf}_{1}$ is shown in Fig. 3a of the Supplement. This field is computed in degrees Celsius as

$$
\begin{aligned}
\operatorname{Tf}_{1}(x, t) & =30.7-0.0081 h_{\mathrm{s}}(x, t)-0.6878|\Phi(x)| \\
& +0.1 \text { TresponseC } \cdot \Delta q_{\mathrm{s}}(t)+\frac{\Delta s(t)}{12.5},
\end{aligned}
$$

where $h_{\mathrm{s}}$ is modelled surface height (m, relative to presentday sea level), and $\Phi$ is latitude $\left(^{\circ}\right)$. To avoid overly low temperatures over the ice shelves, we follow Martin et al. (2011) and remove the dependence on surface elevation when it is below $100 \mathrm{~m}$,

$\operatorname{Tf}_{1}(x, t)=29.89-0.6878|\Phi|+0.1$ TresponseC $\cdot \Delta q_{\mathrm{s}}(t)$

when $h_{\mathrm{s}}(x, t)<100 \mathrm{~m}$.

The second temperature forcing field, $\mathrm{Tf}_{2}$ (Supplement Fig. 3b), is distinguished from $\mathrm{Tf}_{1}$ by the use of the Comiso (2000) present-day surface air temperature map (available as part of ALBMAP) for the AIS ( $T_{\mathrm{PD}}$ ), removal of sea level dependence, and the inclusion of an adjustable vertical temperature gradient via the ensemble parameter lapse rate (Tlapse). The lapse rate range is $5-11^{\circ} \mathrm{Ckm}^{-1}$ (compared with, for example, $9.14{ }^{\circ} \mathrm{Ckm}^{-1}$; Ritz et al., 2001; Pollard and DeConto, 2009 and $8.0^{\circ} \mathrm{Ckm}^{-1}$; Pollard and DeConto, 2012b). Then,

$$
\begin{aligned}
\mathrm{Tf}_{2}(x, t) & =T_{\mathrm{PD}}(x)+0.1 \text { TresponseC } \cdot \Delta q_{\mathrm{S}} \\
& + \text { Tlapse }\left[h_{\mathrm{s}}(x, t)-h_{\mathrm{SPD}}(x)\right]
\end{aligned}
$$

where $\Delta q_{\mathrm{s}}$ and $h_{\mathrm{s}}$ are as for $\mathrm{Tf}_{1}$.

Following Tarasov and Peltier (2004), $\mathrm{Tf}_{3}$ is calculated by interpolating between PD surface temperature (Comiso, 2000) and a Last Glacial Maximum (LGM) air surface temperature field generated from an amalgam of the results of five high-resolution PMIP II (Braconnot et al., 2007) 21 ka simulations (CCSM, HadCM3M2, IPSL-CM4V1-MR, MIROC3.2 and ECHAM53). The 5 datasets are averaged together (Tave $\mathrm{LGM}_{\mathrm{H}}$ ) and we also use the first empirical orthogonal basis function (EOF) of inter-model variance for

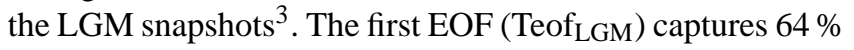
of the total variance and is incorporated through ensemble parameter TeofC (range $-0.5-0.5$ ) into a run-specific LGM reference temperature field $T_{\mathrm{LGM}}$ when the model is initialized,

$T_{\mathrm{LGM}}(x)=\operatorname{Tave}_{\mathrm{LGM}}(x)+$ TeofC $\cdot \operatorname{Teof}_{\mathrm{LGM}}(x)$.

The computed Tave $\mathrm{LGM}_{\mathrm{L}}$ and the associated Teof $f_{\mathrm{LGM}}$ are shown in Supplement Fig. 4. As with $\mathrm{Tf}_{2}$, the present-day and LGM temperature fields are adjusted, through the parameterized lapse rate, to account for the difference between the modelled surface elevation, $h_{\mathrm{s}}$, and the reference surface elevation fields $h_{\mathrm{SPD}}$ and $h_{\mathrm{SLGM}}$ (the PMIP II files are supplied with an associated LGM orthography). The interpolation between the Comiso (2000) present-day temperature field and the model-derived LGM temperature is weighted using a glacial index, $I$, derived from the EPICA temperature record $T_{\text {epica }}$ (Jouzel and Masson-Delmotte, 2007),

$I(t)=\frac{T_{\text {epica }}(t)-T_{\text {epica }}(0)}{T_{\text {epica }}(\mathrm{LGM})-T_{\text {epica }}(0)}$,

and adjusted using ensemble parameter TresponseC giving

$$
\begin{aligned}
\operatorname{Tf}_{3}(\mathbf{X t}, t) & =\left[T_{\mathrm{PD}}(x)+\text { Tlapse } \cdot\left(h_{\mathrm{S}}(x, t)-h_{\mathrm{SPD}}(x)\right)\right] \\
& \cdot(1-(\text { TresponseC } \cdot I(t)) \\
& +\left[T_{\mathrm{LGM}}(x)+\text { Tlapse } \cdot\left(h_{\mathrm{S}}(x, t)-h_{\mathrm{SGM}}(x)\right)\right] \\
& \cdot(\text { TresponseC } \cdot I(t)) .
\end{aligned}
$$

\footnotetext{
${ }^{3}$ This is a numerical technique to decompose in this case the maps of LGM temperature from the set of PMIP GCM runs into a series of orthogonal spatial maps, ordered with respect to minimizing the residual variance of the subsequent maps in the series. Thus the first EOF captures in some sense the maximum mode of inter-model differences.
} 
As compared to the time-dependence of $\mathrm{Tf}_{1}$, the $I(t)$ glacial index (cf. Supplement Fig. 2) has more highfrequency variability along with a tendency to a pre-LGM cold-bias except for a stronger warming during the Eemian. The three temperature fields are then combined in accordance with two ensemble parameters, Tmix1 and Tmix2 (both range 0-1), to produce the final temperature field,

$$
\begin{aligned}
T(x, t) & =(1-\mathbf{T m i x} 2) \cdot\left[\mathbf{T m i x} 1 \cdot \operatorname{Tf}_{1}(x, t)\right. \\
& \left.+(1-\mathbf{T m i x} 1) \cdot \operatorname{Tf}_{2}(x, t)\right]+\operatorname{Tmix} 2 \cdot \operatorname{Tf}_{3}(x, t) .
\end{aligned}
$$

The extra weight given to $\mathrm{Tf}_{3}$ in the above was chosen on the basis of simplicity and the much more similar temporal dependencies (mostly via orbital insolation anomalies) of $\mathrm{Tf}_{1}$ and $\mathrm{Tf}_{2}$.

\subsubsection{Precipitation forcing}

The precipitation forcing is also subject to a weighted amalgam of three different forcings. $\mathrm{Pf}_{1}$ assumes precipitation is driven by temperature (as per Huybrechts et al., 1998),

$\operatorname{Pf}_{1}(x, t)=1.5 \times 2^{\frac{T(x, t)-T_{\mathrm{m}}}{10}}$.

where $T$ is the blended temperature and $T_{\mathrm{m}}$ is $0^{\circ} \mathrm{C}$. This relationship is motivated by the exponential dependence of the saturation vapour pressure on temperature. Present-day $\mathrm{Pf}_{1}$ is shown in Supplement Fig. 3c.

$\mathrm{Pf}_{2}$ is computed in a similar manner to $\mathrm{Tf}_{2}$; at run-time, an observational dataset, $P_{\mathrm{PD}}$ (shown in Supplement Fig. 3d), of present-day precipitation (Arthern et al., 2006) is adjusted using the annual orbital insolation anomaly. Ensemble parameter PphaseEXP (range 0.5-2) accounts for some response uncertainty to the insolation anomaly,

$\operatorname{Pf}_{2}(x, t)=P_{\mathrm{PD}}(x) \times 2^{\operatorname{PphaseEXP} \frac{\Delta q_{\mathrm{s}}(t)}{100}}$.

In a similar manner to $\mathrm{Tf}_{3}, \mathrm{Pf}_{3}$ is computed using the glacial index $I(t)$ to interpolate between the present-day dataset $P_{\mathrm{PD}}$ and an LGM precipitation field, generated from an amalgam of the PMIP II LGM precipitation simulations,

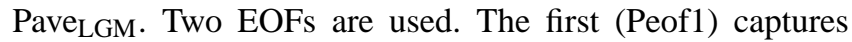
$62 \%$ of the inter-model variance, the second (Peof2) captures

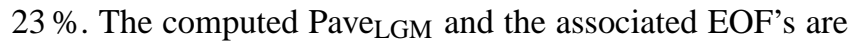
plotted in Supplement Fig. 5. As with $\mathrm{Tf}_{3}$ the EOFs are introduced at model initialization through parameters Peof1C and Peof2C (range $-0.5-0.5$ ) to create a run specific reference dataset,

$$
\begin{aligned}
P_{\mathrm{LGM}}(x) & =\text { Pave }_{\mathrm{LGM}}(x)+\text { Peof1C } \cdot \operatorname{Peof}_{\mathrm{LGM}}(x) \\
& + \text { Peof2C } \cdot \operatorname{Peof} 2_{\mathrm{LGM}}(x) .
\end{aligned}
$$

This is scaled and adjusted using ensemble parameter PresponseC (range 0.5-2),

$\operatorname{Pf}_{3}(x, t)=P_{\mathrm{PD}}(x)\left(\operatorname{PresponseC} \frac{P_{\mathrm{LGM}}(x)}{P_{\mathrm{PD}}(x)}\right)^{\mathrm{Pfac}}$, where Pfac is the glacial index exponentially scaled by ensemble parameter PphaseEXP (range 0.5-2),

Pfac $=\operatorname{sign}[1.0, I(t)]|I(t)|^{\text {PphaseEXP }}$.

The final precipitation field is then summed and interpolated using two ensemble parameters Pmix1 and Pmix2,

$$
\begin{aligned}
P(x, t) & =q_{\mathrm{des}} \cdot\left(( 1 - \mathbf { P m i x } 2 ) \cdot \left[\operatorname{Pmix} 1 \cdot \operatorname{Pf}_{1}(x, t)\right.\right. \\
& \left.\left.+(1-\text { Pmix1 }) \cdot \operatorname{Pf}_{2}(x, t)\right]+\operatorname{Pmix} 2 \cdot \operatorname{Pf}_{3}(x, t)\right),
\end{aligned}
$$

where $q_{\text {des }}$ accounts for the elevation-desert effect (reduced amount of moisture the atmosphere can hold at elevation) (Marshall et al., 2002; Tarasov and Peltier, 2004). It is simulated as a function of the modelled elevation anomaly from present day,

$q_{\mathrm{des}}=\exp ^{- \text {PdeselevEXP. }\left(h_{\mathrm{s}}(x, t)-h_{\mathrm{SPD}}(x)\right)}$,

and ensemble parameter PdeselevEXP $\left(0-2 \times 10^{-3}\right)$.

The final "blended" temperature and precipitation fields are used to determine the fraction of precipitation that falls as snow and the annual surface melt. Given the small amount of surface melt over the AIS (Zwally and Fiegles, 1994), a simplified positive-degree-day method (PDD) is used with a melt factor of $5 \mathrm{~mm} \mathrm{PDD}^{-1}$.

\subsection{Ice-ocean interface}

The vast majority of mass loss from the AIS occurs from the ice shelves, either due to calving at the ice margin or from submarine melting beneath the ice shelf (Jacobs et al., 1992). The ice shelves play a crucial role in restricting (buttressing) the flow of ice (Dupont and Alley, 2005). Reduction or removal of the shelves allows the upstream grounded ice to accelerate, drawing down the ice in the interior. Thus, changes at the ice-ocean interface can have an impact hundreds of kilometres inland (Payne et al., 2004).

Iceberg calving has been inferred to be the largest contributor to mass loss. Jacobs et al. (1992) apportioned a loss of $2016 \mathrm{Gtyr}^{-1}$ to calving against $544 \mathrm{Gtyr}^{-1}$ to sub-iceshelf melt (the uncertainty estimates for these numbers are large, $\pm 33 \%$ for iceberg calving and $\pm 50 \%$ for sub-ice-shelf melt). However, there is growing concern and evidence that the sub-ice-shelf melt rate is a primary control on the mass loss (Pritchard et al., 2012). Both processes are modelled in the GSM.

\subsubsection{Calving}

Marine ice margins can either terminate as a floating ice shelf or as a tidewater glacier. The GSM uses two distinct parameterizations to calculate mass loss from either of these regimes; in addition there is an ad hoc treatment for thin ice.

\section{Ice shelf calving}

Though there have been significant efforts towards a fully constrained, physically based calving model for ice shelves 
every timestep

for each shelf (AMY,ROS, RON, FIL,OTHERS) and for each cell
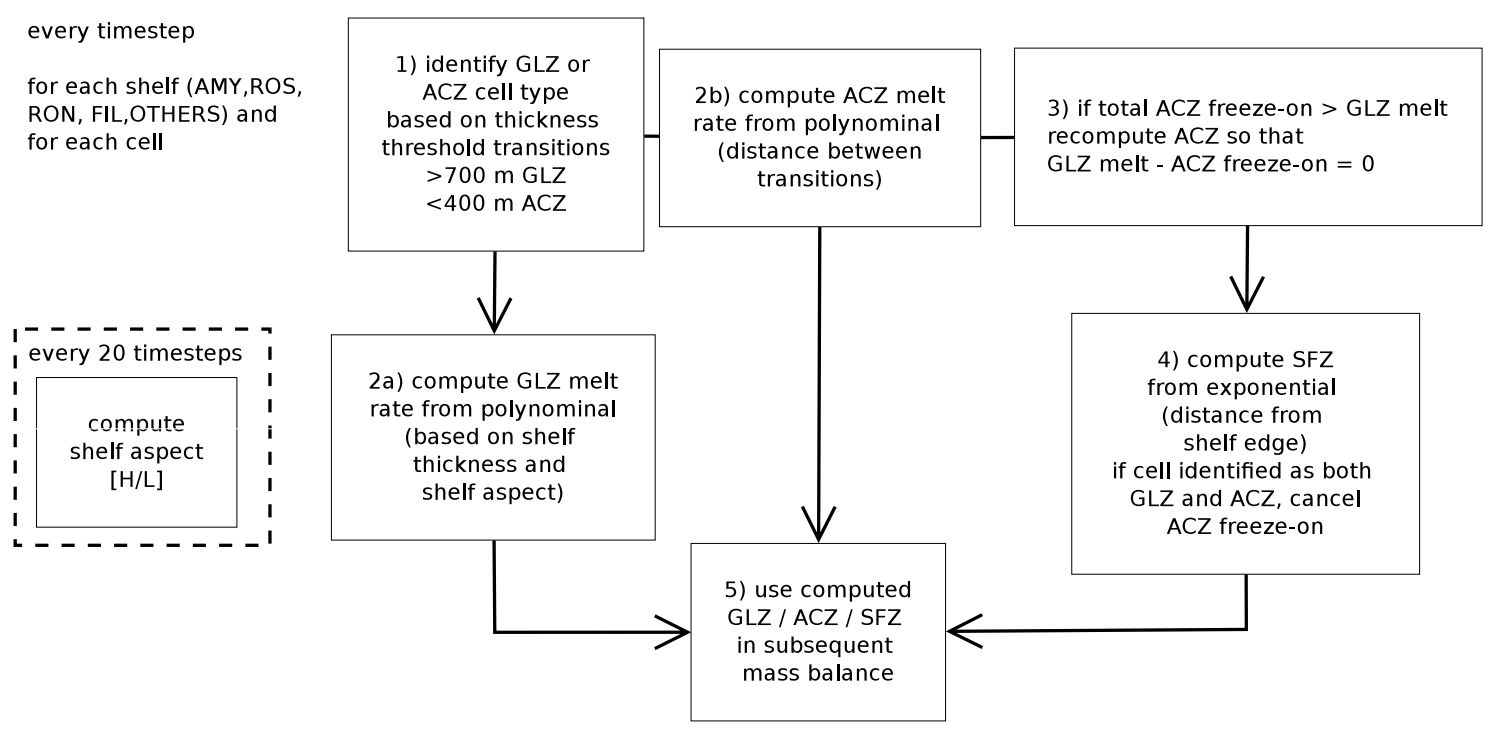

Fig. 2. SSM (sub-ice-shelf melt) implementation flowchart, with details for each distinct process zone: GLZ (grounding line zone), ACZ (accretion), and SFZ (shelf front).

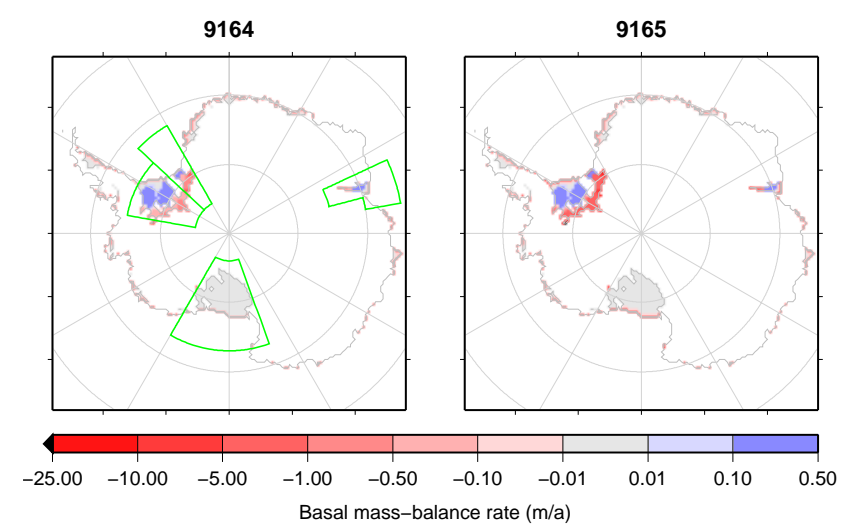

Fig. 3. Melt rate maps generated from lower (9164) and upper (9165) SSM parameter values. The large shelf regions are outlined in green (the latitude, $\Phi$, and longitude, $\lambda$, boundaries are $\mathrm{AMY}=$ $\Phi(-75,-65), \lambda(65,75)$ and $\Phi(-75,-70), \lambda(75,80) ; \quad$ ROS $=$ $\Phi(-86,-73), \lambda(160,210) ; \quad \mathrm{RON}=\Phi(-85,-75), \lambda(280,313)$ and FIL $=\Phi(-72,-85), \lambda(313,330))$.

(e.g. Alley et al., 2008; Albrecht et al., 2011; Amundson and Truffer, 2010), we have found none to be stable for the relatively coarse grid of the GSM. For the present model configuration, ice shelf calving is based on a steady-state approximation of Amundson and Truffer (2010, Eq. 25) which corresponds to the insertion of the Sanderson (1979) relationship for ice shelf half-width into the empirical relation of Alley et al. (2008). Calving velocity is determined for each exposed face of the marginal grid cell. For a calving face normal to the $x$ axis, it is computed as

$U_{\mathrm{c}}=-H_{0} \dot{\epsilon}_{x x}\left(\frac{\partial H}{\partial x}\right)^{-1}$,
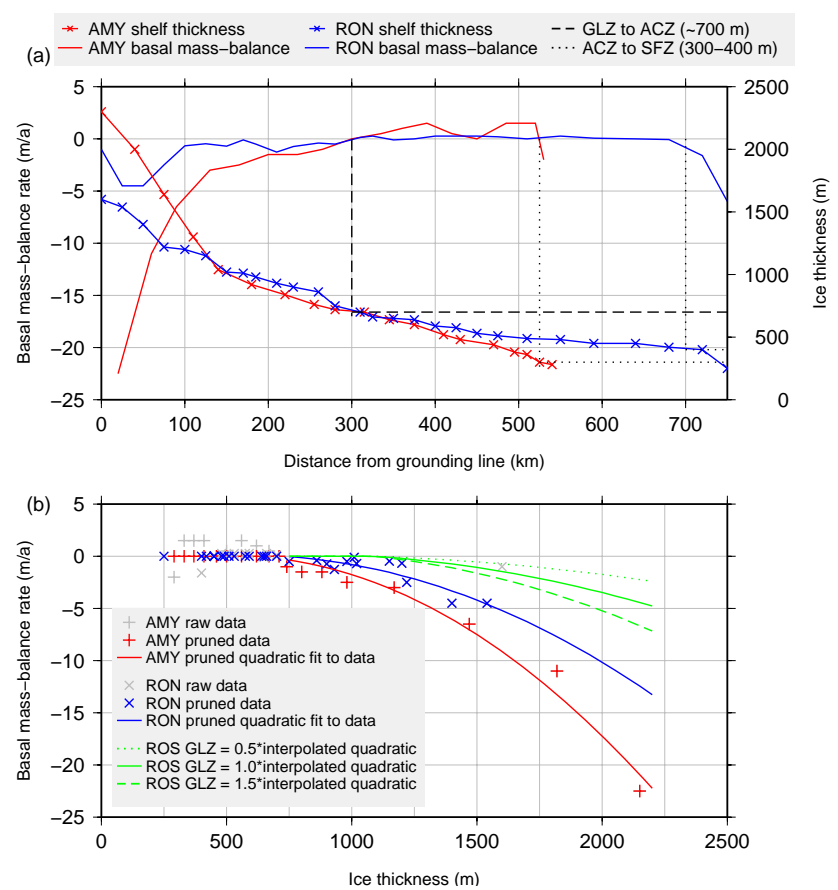

Fig. 4. Plots showing the (a) melt rate and thickness transects and (b) the GLZ quadratic law. The transects are as extracted from source publications for AMY (Wen et al., 2007) and for RON (Jenkins and Doake, 1991). The transitions, from which the threshold thicknesses are estimated, from GLZ to ACZ and ACZ to SFZ are shown in plot (a). For the quadratic fits, once the basal mass balance rate is $>0 \mathrm{~m} \mathrm{yr}^{-1}$ (i.e. onset of freeze-on and thus part of the $\mathrm{ACZ}$ ), the remaining data points are all set to zero. The quadratic fit is made to this pruned dataset. 

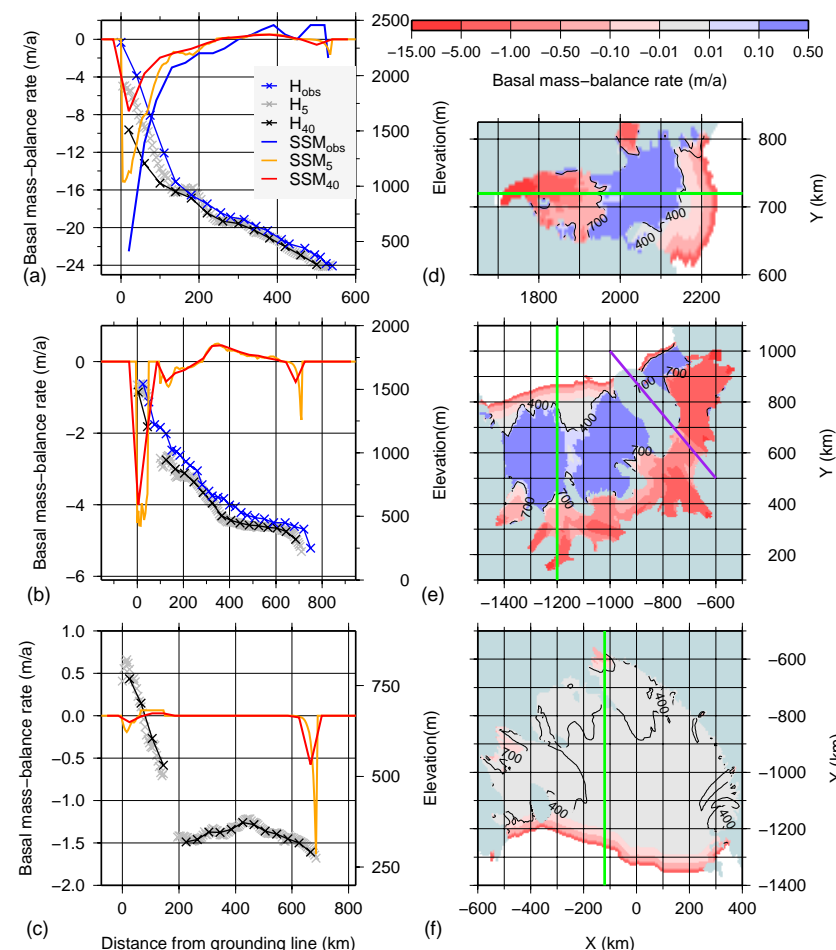

Fig. 5. Transects of thickness and observed/computed melt rates, and computed spatial melt maps for the three major shelves: AMY (a, d), ROS (b, e), RON-FIL (c, f) computed from the SSM law with unity parameters (see text). $H_{\mathrm{obs}}, \mathrm{H}_{5}$, and $\mathrm{H}_{40}$ are the thicknesses from the observed, ALBMAP 5 , and ALBMAP 40 datasets. $\mathrm{SSM}_{\mathrm{obs}}$ is the observed melt rates. $\mathrm{SSM}_{5}$ and $\mathrm{SSM}_{40}$ are the computed melt rates based on the respective ALBMAP thicknesses. Green line on the melt maps shows the locations of the transects. The purple line demarcates the divide between the FIL and RON shelves at $47^{\circ} \mathrm{W}$. The black contours highlight the observed 400 and $700 \mathrm{~m}$ thickness contours.

where $H_{0}$ is the terminus ice thickness and $\dot{\epsilon}_{x x}$ is the alongflow spreading rate (so $U_{\mathrm{c}} \geq 0$ ). Due to the coarse grid resolution, $\dot{\epsilon}_{x x}$ and $\left(\frac{\partial H}{\partial x}\right)^{-1}$ are computed one grid cell upstream from the terminus. The calving rate (ice loss per grid cell area, $\geq 0)$, adjusted by ensemble parameter shelfcalvC $(0.5-$ $2.5)$, is computed as

$\dot{C}=\operatorname{shelfcalvC} \cdot U_{\mathrm{c}} \cdot \frac{H_{0}}{\Delta x}$.

$\Delta x$ is the the terminal grid cell length perpendicular to the calving face. Once calculated $\dot{C}$ is used in the mass balance equation (Pollard and DeConto, 2012b, Eq. 14).

For ice thinner than $300 \mathrm{~m}$ the calving rate computed above is enhanced. Given the present-day correspondence between average ice shelf front and the mean annual $-5^{\circ} \mathrm{C}$ isotherm (Mercer, 1978), for ice thinner than $300 \mathrm{~m}$ and thicker than ensemble parameter Hshelfcrit $(10-150 \mathrm{~m})$, we impose a simple temperature-dependent $\left(T_{\mathrm{S}}\right.$, sea surface mean summer temperature in ${ }^{\circ} \mathrm{C}$ ) parameterization.
For ice thinner than Hshelfcrit, calving is enhanced by a term shelfcalv2C $\cdot H$, where ensemble parameter shelfcalv2C ranges from 0 to $0.2 \mathrm{yr}^{-1}$. Thus, the ice shelf calving rate is

$$
\dot{C}_{\mathrm{IS}}=\left\{\begin{array}{l}
\dot{C}, \quad \text { if } H \geq 300 \\
\dot{C}+\max \left\{\left(T_{\mathrm{S}}+3^{\circ}\right) \frac{H}{5^{\circ}} \cdot 1 \mathrm{yr}^{-1}, 0\right\}, \text { if Hshelfcrit } \leq H<300(21) \\
\dot{C}+\text { shelfcalv2C } \cdot H, \quad \text { if } H<\text { Hshelfcrit. }
\end{array}\right.
$$

The ad hoc nature of the above arose out of trial-and-error attempts to ensure a large range of calving response was attainable. As for all the parameterizations presented herein, the judgement criteria is plausibility given current understanding and coverage of potential dynamical response over ensemble parameter ranges.

\section{Tidewater calving}

For grounded marine ice margins (i.e. large-scale tidewater glaciers), we use a slight variant of the temperaturedependent proximity-to-flotation model of Tarasov and Peltier (2004). This parameterization is motivated by the proximity-to-flotation paradigm of tidewater calving (Van der Veen, 2002) along with an exponential temperature threshold to loosely account for the effects of sea ice and submarine melting, and the impact of surface water on crack propagation. Three conditions are imposed for such calving: (1) an adjacent ice-free grid cell with water depth greater than $20 \mathrm{~m},(2)$ summer sea surface temperature $T_{\mathrm{S}}$ above a critical minimum value $T_{\mathrm{Cmn}}$ and (3) ice thickness less than 1.15 times the maximum buoyant thickness, $H_{\text {flot }}$. When the above conditions are met, the calving velocity is given by

$$
\begin{aligned}
U_{\mathrm{c}} & =\mathbf{c a l v m a x} \mathbf{V} \cdot \min \left[1,\left(\frac{1.15 H_{\text {flot }}-H}{0.35 H_{\text {flot }}}\right)^{2}\right] \\
& \times\left(\exp \left(\frac{3 \cdot\left(T_{\mathrm{s}}-T_{\mathrm{Cmx}}\right)}{T_{\mathrm{Cmx}}-T_{\mathrm{Cmn}}}\right)-\exp (-3)\right) /(1-\exp (-3)) .
\end{aligned}
$$

The response of the above parameterization to ice thickness and summer sea surface temperature is visually documented in Supplement Fig. 6. Calving is active at each grid cell edge meeting the calving conditions above and uses the maximum calving velocity, calvmaxV, as the single ensemble parameter (range $0.1-10 \mathrm{~km} \mathrm{yr}^{-1}$ ). Based on best fits from previous ensembles and some physical judgement (with allowance for sub-seasonal SST variations), $T_{\mathrm{Cmn}}$ is set to $-5^{\circ} \mathrm{C}$ and $T_{\mathrm{Cmx}}$ to $2{ }^{\circ} \mathrm{C}$. We also invoke an ad hoc extrapolation of ice thickness to the calving margin (as model ice thickness is defined at grid cell centres) for conversion of calving velocity to a mass balance term (since mass loss $=U_{\mathrm{c}} \times$ calving front ice thickness $\times$ length of calving front). The ice thickness at the calving front for this conversion is computed as a smooth quadratic reduction of the grid cell thickness for ice thicker than $400 \mathrm{~m}$ with a maximum marginal ice thickness of $900 \mathrm{~m}$ for grid cells with ice thicker than $1400 \mathrm{~m}$. In detail, within the above range, the marginal ice thickness is set to $900-500 \cdot((1400-H) / 1000)^{2}$. 


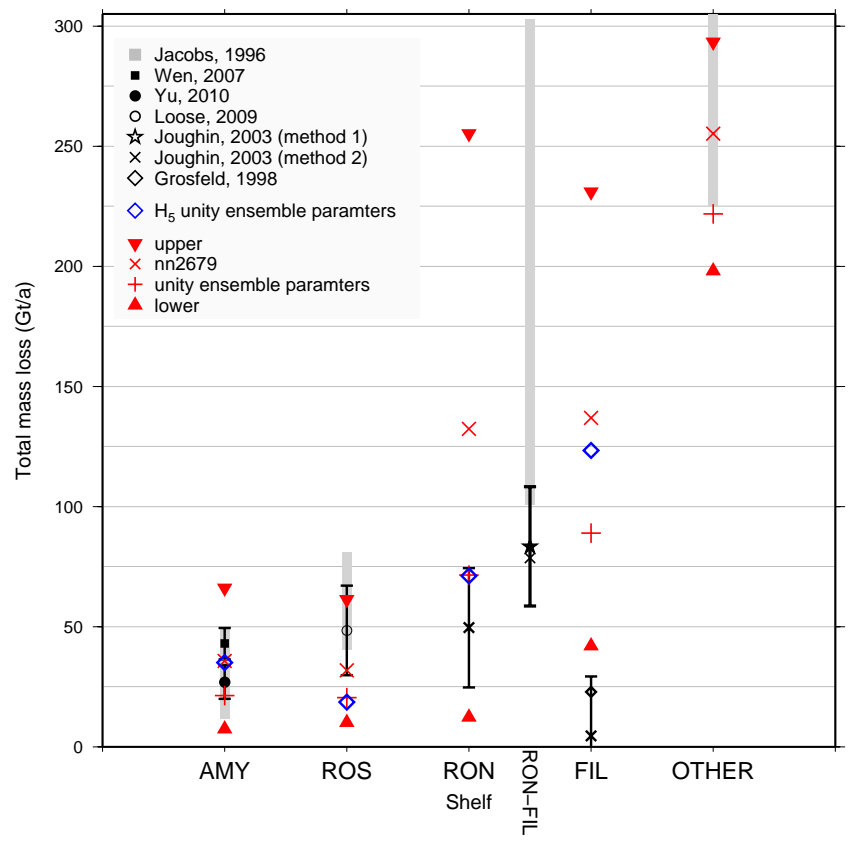

Fig. 6. Comparison plot showing net melt amounts from observations and the predicted melt amount from the SSM component for each of the five shelf regions; two observations that are for the cumulative RON-FIL are also shown. The OTHER observation has been clipped as the maximum, estimated from Jacobs et al. (1996), peaks at $675 \mathrm{Gt} \mathrm{yr}^{-1}$ (see Supplement Table 4).

\section{Thin ice treatment}

The ice shelf calving modules, and the sub-ice-shelf component described in the next section, were not designed for excessively thin (in this case $<10 \mathrm{~m}$ thick) ice and we found it necessary to add a separate parameterization for this case. Again using the present-day correspondence between average ice shelf front and the $-5^{\circ} \mathrm{C}$ isotherm (Mercer, 1978), we imposed a simple temperature-dependent parameterization. For marine ice $<10 \mathrm{~m}$ thick, the calving rate is

$$
\begin{aligned}
\dot{C}_{\mathrm{r}} & =\max [\text { calving rate from other modules, } 0.3 \\
& +\mathrm{zclim}(t) \cdot \text { calvthinC }],
\end{aligned}
$$

where calvthinC is a calibration parameter with a range 3$10 \mathrm{~m} \mathrm{yr}^{-1}$ and zclim is an interglacial index factor (value 1 at $0 \mathrm{ka}$, value 0 at LGM, it is compared to other glacial indices presented above in Supplement Fig. 2). It is computed, as per Pollard and DeConto (2009), from the sea level departure from present $(\Delta s)$ with some influence from the January orbital insolation anomaly $\left(\Delta q_{\mathrm{jan}}\right)$ :

$$
\begin{aligned}
\operatorname{zclim}(t) & =\max \left[0, \min \left[1.5,1+\frac{\Delta s(t)}{85}\right.\right. \\
& \left.\left.+\max \left[0, \frac{\Delta q_{\mathrm{jan}}(t)}{40}\right]\right]\right] .
\end{aligned}
$$

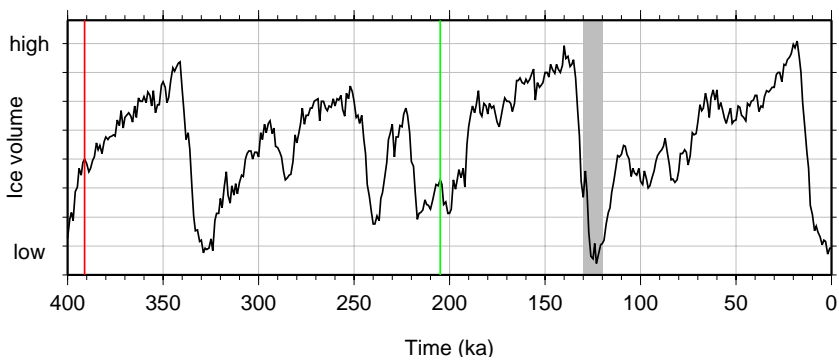

Fig. 7. Lisiecki (2005) stacked benthic $\delta^{18} \mathrm{O}$ record as proxy for global ice volume showing key times for spin-up run. For the generation of the spin-up ensemble (see text for details), ice dynamics are only intermittently active from $391 \mathrm{kyr}$ (red) until $205 \mathrm{kyr}$ (green). For the ensemble proper, initialization starts at $205 \mathrm{kyr}$. Approximate period of the Eemian is highlighted in grey.

\subsubsection{Sub-ice-shelf melt}

Sub-ice-shelf melt (SSM) is a reaction to a complex interaction of oceanographic and glaciological conditions and processes. The newly developed SSM component used in MUN/PSU is a physically motivated implementation based on empirical observations. As such we provide a brief review of the SSM process to justify the implementation.

Three modes of melt have been identified (Jacobs et al., 1992). Mode 1 melt occurs in the grounding line zone of the larger shelves; driven by thermohaline circulation, it is triggered by the formation of high-salinity continental shelf water (HSSW). As sea ice forms near the ice shelf edge, brine rejection occurs, producing the dense HSSW. The water mass sinks and, upon reaching the continental shelf, drifts underneath the ice shelf into the grounding line cavity (the continental shelves generally slope down toward the grounding line due to long-term erosion by ice advances and to a lesser degree from isostatic depression). Due to the pressure dependence of the freezing point of water, the in situ melting point of the ice shelf base is lower than the temperature of the HSSW (formed at sea surface temperatures of e.g. $\sim-1.9^{\circ} \mathrm{C}$ ). The encroaching water mass, acting as a heat delivery mechanism, melts away at the ice shelf base (Jacobs et al., 1992; Rignot and Jacobs, 2002; Joughin and Padman, 2003; Holland et al., 2008). The melting ice freshens (and cools) the surrounding water mass, producing buoyant ice shelf water (ISW), which, if not advected away, rises up and shoals along the base of the ice shelf. As the water mass rises the ambient pressure decreases, increasing the in situ freezing point until refreezing occurs, and new marine ice accretes onto the base of the ice shelf (Jacobs et al., 1992; Joughin and Padman, 2003).

The three largest shelves, Amery (AMY), Ross (ROS), and Ronne-Filchner (RON-FIL), differ greatly in draught and cavity geometry, and have distinct melt regimes (Horgan et al., 2011). The long, narrow AMY shelf is smallest by area but has a relatively deep draught of $\sim 2200 \mathrm{~m}$ (Fricker 
et al., 2001). Grounding line melt rates of $31 \pm 5 \mathrm{~m} \mathrm{yr}^{-1}$ have been estimated and accreted marine ice with a thickness up to $190 \mathrm{~m}$ have been calculated (Rignot et al., 2008; Fricker et al., 2001). ROS is the largest ice shelf by area but is much shallower with a draught of about $800 \mathrm{~m}$; the melt rates are greatly reduced as is the marine ice accretion $(\sim 10 \mathrm{~m}$; Neal, 1979; Zotikov et al., 1980). RON and FIL both have deep grounding lines $\sim 1400 \mathrm{~m}$ and melt rates that can exceed $5 \mathrm{myr}^{-1}$ at some locations, the accreted marine ice can exceed $>300 \mathrm{~m}$ under RON, but, unlike AMY, it does not persist to the ice shelf front (Thyssen et al., 1993; Lambrecht et al., 2007).

Mode 2 and mode 3 melting occur both under the smaller shelves that fringe the AIS (e.g. those that face the Amundsen, Weddell, and Bellingshausen seas) and proximal to the zone near the calving margin of the larger shelves. Mode 2 melting is associated with the intrusion of "warm" circumpolar deep water (CDW) at intermediate depths (Jacobs et al., 1992; Jacobs et al., 1996; Joughin and Padman, 2003). The degree of melt is dependent on the amount of heat that can be delivered into the ice cavity, itself a function of oceanographic conditions and the proximity of the ice base to the continental shelf edge. The highest melt rates occur at the grounding lines of the Pine Island $\left(44 \pm 6 \mathrm{~m} \mathrm{yr}^{-1}\right)$ and Thwaites $\left(34 \pm 9 \mathrm{~m} \mathrm{yr}^{-1}\right)$ glaciers that discharge into the Amundsen Sea (Rignot and Jacobs, 2002). The grounding lines, at a depth of about $1000 \mathrm{~m}$, are melted by the intrusion of CDW water that is almost $4{ }^{\circ} \mathrm{C}$ above the in situ melting point (Rignot and Jacobs, 2002). Mode 3 melting is produced by seasonally warm surface water being advected against and underneath the ice shelf edge, through the action of tidal pumping and coastal currents (Jacobs et al., 1992). Melt rates of $2.8 \mathrm{~m} \mathrm{yr}^{-1}$, decaying exponentially down to zero around $40 \mathrm{~km}$ upstream from the calving margin, have been estimated for ROS. This is $10-40 \%$ of the published total melt estimates for ROS (Horgan et al., 2011).

There is clear evidence that regional oceanographic forcing of the contemporary AIS is important (e.g. Pine Island, western Antarctic Peninsula) and growing evidence that similar regional forcing occurred during deglaciation (e.g. Walker et al., 2008; Nicholls et al., 2009; Jenkins et al., 2010; Pritchard et al., 2012). To accurately model SSM over glacial cycles would require a high-resolution coupled GSM and ocean model that are able to represent the major components (e.g. evolving cavity geometry; heat and salt flux exchange between the ice base, the cavity water masses, and the open ocean) of the SSM process (Holland et al., 2003; Payne et al., 2007; Olbers and Hellmer, 2010; Dinniman et al., 2011). This approach is at present not computationally feasible. Recent studies with GSMs configured for the AIS have used either parameterized ad hoc implementations (Pollard and DeConto, 2009) or variants of the simplified melt equation proposed by Beckmann (2003) (Martin et al., 2011; Pollard and DeConto, 2012b). The Beckmann equation was developed to model the ice-shelf-ocean interface. It yields a melt
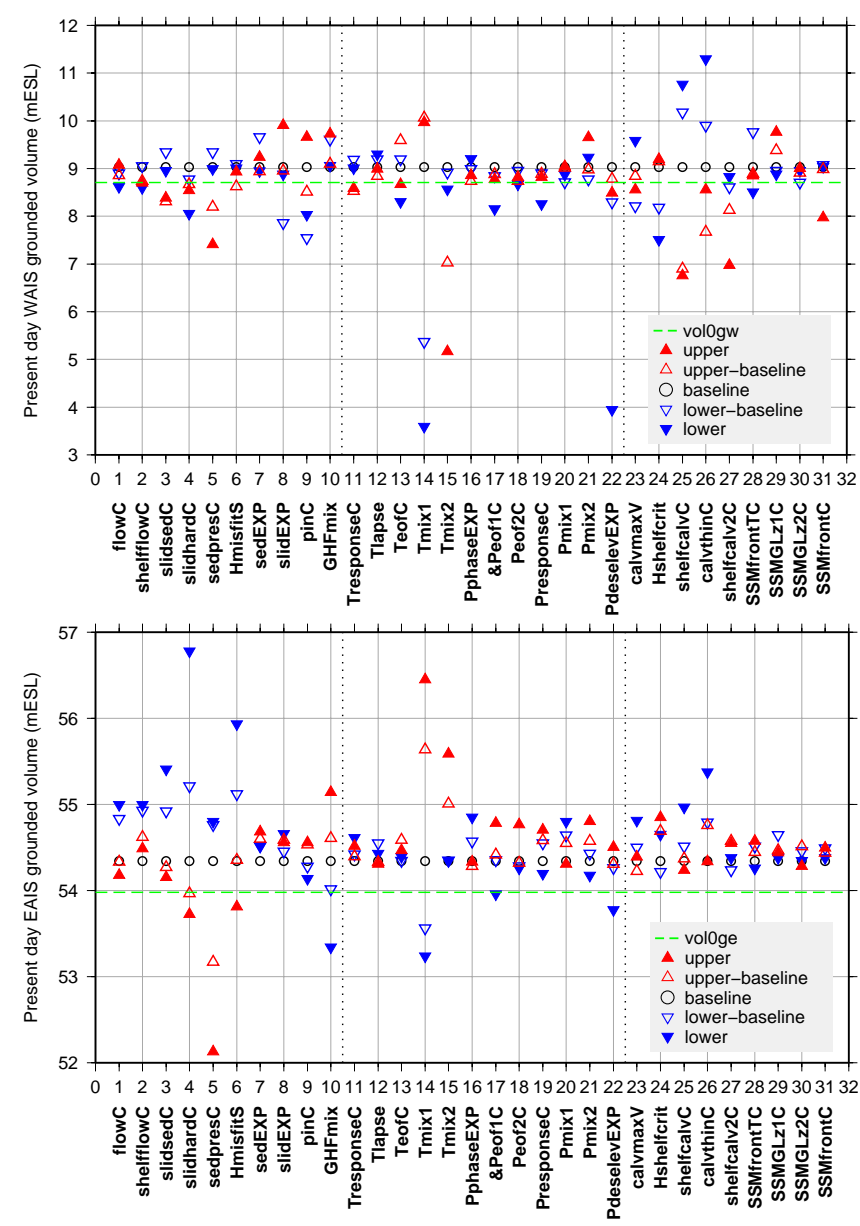

Fig. 8. Sensitivity results for present-day WAIS (upper) and EAIS (lower) grounded ice volume. The dotted lines segregate the parameters into blocks pertaining to ice physics, climate forcing and ice-ocean forcing. Observational metrics values (dashed green line) are computed from $\mathrm{H}_{40}$.

rate dependent on the heat flux between the ice shelf bottom and the ocean. The PISM-PIK ice sheet model used a variant of this law, forced by a continent-wide constant ocean temperature adjusted by the pressure-dependent freezing point of ocean water, to produce an SSM spatial distribution dependent on the draught of the ice shelf (Martin et al., 2011). The PSU GSM evolved the PISM-PIK method by, amongst other changes, introducing specific regions of ocean temperatures based on observations; this reportedly gives quite reasonable modern day SSM values (Pollard and DeConto, 2012b). For palaeo-climatic simulations the regional ocean temperatures were hindcast backward proportional to the Lisiecki (2005) stacked benthic $\delta^{18} \mathrm{O}$ records. The Beckmann law does not capture the freeze-on nor the effect of enhanced ice shelf front melt.

For the MUN/PSU GSM, a SSM component was developed that did not have a strong dependence on oceanic temperatures. This removed the associated parameters required 


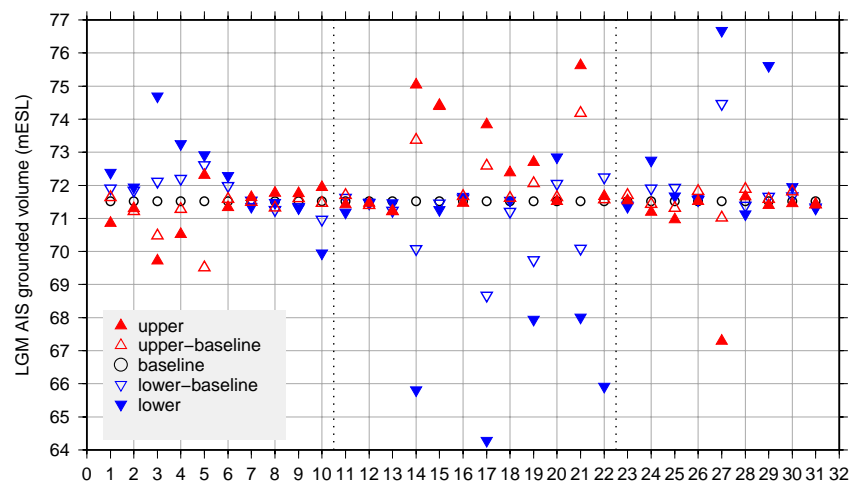

$00000000 \times 00007000079=000000$
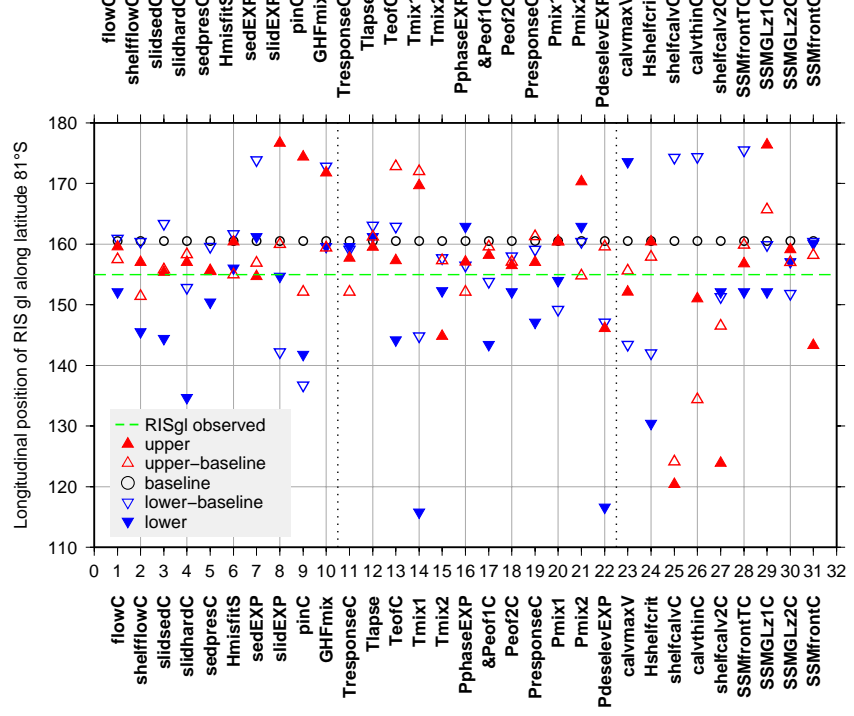

Fig. 9. Sensitivity results for total AIS grounded volume (upper) at LGM and present-day ROSgl position (lower). Note the latter metric misfit from observation for the baseline run is $\sim 100 \mathrm{~km}$, which equates to 2-3 grid cells.

to provide both regional tuning of the shelves and palaeoadjustment. The new SSM component is a physically motivated empirical approach that captures both the melt-freezemelt regimes of the larger shelves and the simpler melt regimes of the peripheral shelves. There are three ensemble parameters to provide some degrees of freedom in the component. The geometry of the larger shelves is used to adjust the strength of the melt aspect ratio, allowing some regional and temporal evolution.

\section{SSM implementation}

We merge the exponential ice shelf front melt law published by Horgan et al. (2011) ${ }^{4}$ with quadratic fits to distance-from-

\footnotetext{
${ }^{4}$ The exponential ice shelf melt law was derived from spatial and temporal variations, measured by ICESat laser altimetry data, of the ice surface at the front of the ice shelf. The surface changes were attributed to enhanced basal melt within $60 \mathrm{~km}$ of the ice shelf front (Horgan et al., 2011).
}
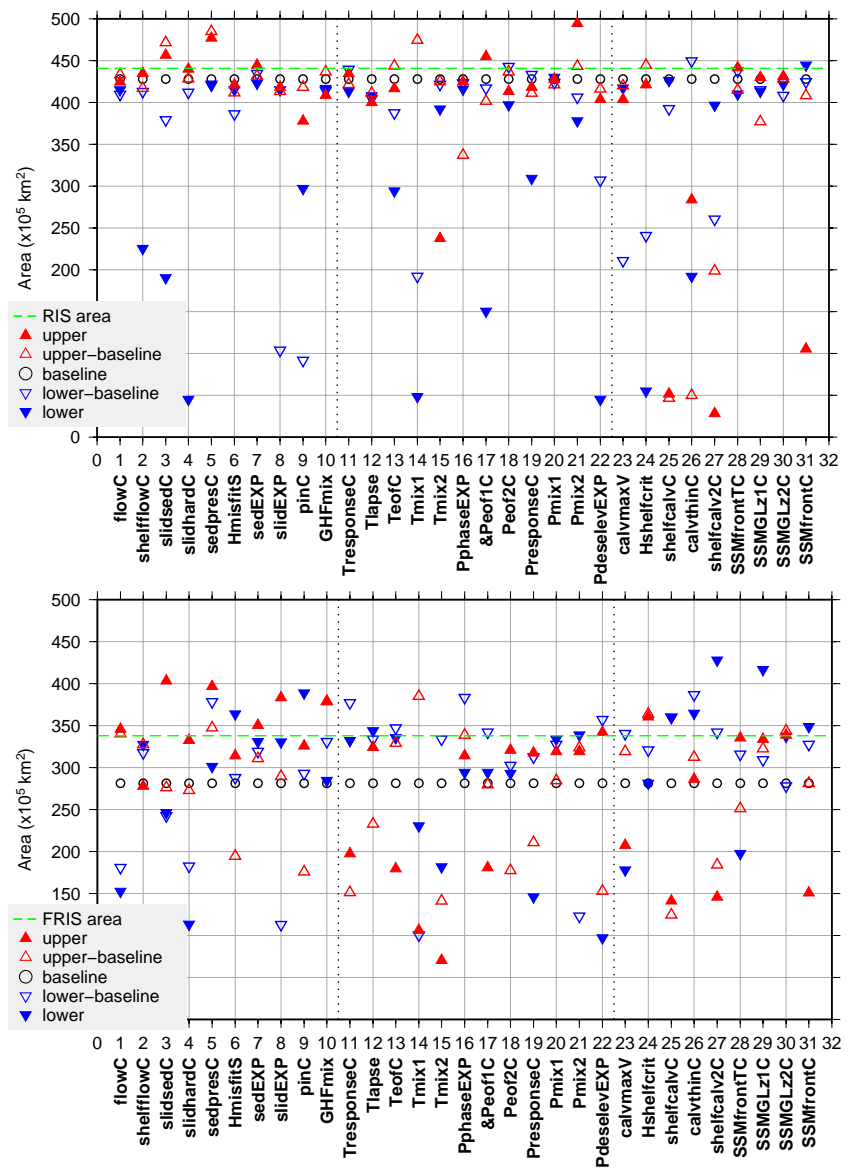

Fig. 10. Sensitivity results for ROS (upper) and RON-FIL (lower) present-day area.

grounding line transects for the melt rate and the ice shelf thickness measured for AMY (Wen et al., 2007) ${ }^{5}$ and RON (Jenkins and Doake, 1991) ${ }^{6}$. A flowchart of the implementation is shown in Fig. 2.

The SSM component models three regimes under the larger shelves: a draught-dependent grounding line zone (GLZ) of melt, an accretion zone (ACZ) where freeze-on occurs, and a zone of melt at the ice shelf front (SFZ). The smaller shelves only have regions of GLZ and SFZ melt occurring. Being on the periphery of the continent, the smaller

\footnotetext{
${ }^{5}$ The AMY transects were computed from in situ and remote sensing datasets; a flow line set of flux gates were defined using the datasets. The mass budgets, basal melting, and freezing rates were derived from the flux gates (Wen et al., 2007).

${ }^{6}$ The RON transects were derived from a glaciological field study of 28 sites that lie along flow lines extending from the grounding line to the ice shelf front. The objective of the study was to derive ice-ocean interaction behaviour from surface measurements. Physical characteristics, including the thickness data, were measured at each site and the data were used in a kinematic steady-state model to derive the basal mass flux (and other fields) (Jenkins and Doake, 1991).
} 
shelves lack the embayment protection that the larger shelves have. As such, the sub-ice-shelf environment is not sufficiently quiescent to allow the mode 1 melt water to freeze-on underneath the ice shelf. For monitoring modelled ice shelf response, the floating ice is divided into five regions (shown in Fig. 3a) pertaining to the four large shelves (AMY, ROS, RON, and FIL), and the ice that is not part of the large shelves (e.g. the smaller shelves of the Amundsen, Weddell, and Bellingshausen seas and the remaining unnamed shelves) is classified as OTHER.

The transitions between the zones were estimated from the AMY and RON transects, shown in Fig. 4a. The raw data for these transects, given in Tables 1 and 2 of the Supplement, were extracted from Wen et al. (2007, Figs. 4 and 6) for AMY and from Jenkins and Doake (1991, Figs. 9 and 10) for RON.

The transition from GLZ to ACZ in the larger shelves occurs at a shelf thickness of $\sim 700 \mathrm{~m}$. Similarly the transition from the ACZ to the SFZ occurs at a shelf thickness of approximately $300-400 \mathrm{~m}$. The melt-accretion-melt pattern can also be seen, albeit approximately, when comparing the $700 \mathrm{~m}$ and/or $300 \mathrm{~m}$ contour from ALBMAP (Fig. 5) and the satellite-derived melt distribution patterns of AMY (Fricker et al., 2001, Fig. 3), FIL (Joughin and Padman, 2003, Fig. 2), and the modelling study of ROS (Holland et al., 2003, Fig. 10). Sensitivity tests were made adjusting the transition thicknesses within the range of uncertainty in the transects. However, because the melt/accumulation rates before and after the transition zones are very small (Jacobs et al., 1992; Horgan et al., 2011; the dominant melt rates occur at the grounding lines and at the shelf front), there was little impact. As such the transition thicknesses are held constant in the SSM component.

The melt rate in the GLZ is modelled as a function of ice shelf thickness and the aspect ratio of the ice shelf. Plotting the melt rate as a function of thickness (Fig. 4b) allows a quadratic best fit to be made (the raw data were pruned so that the quadratic fit is only made with the data that are upstream of the GLZ-to-ACZ transition thickness threshold; i.e. where $H<700 \mathrm{~m}$ the melt rate is set to zero); each transect has a different fit, and thus each ice shelf has a different melt rate thickness function. We hypothesize that, because the larger shelves have distinct cavity geometries that affect the oceanographic processes within them (Fricker et al., 2001; Horgan et al., 2011), the melt function is proportional to the physical dimensions of the ice shelf. We define a thicknessto-length aspect ratio, $\epsilon=[H] /[L]$, to reflect the cavity dimensions. Table 4 summarizes the physical characteristics, computed from ALBMAP, used for defining the aspect ratio. The average length is computed as the average minimum distance from each grounding line grid cell to open ocean without encountering land or grounded ice. The ice shelf average melt rate magnitudes are taken from Table 3 of the Supplement. The stronger melt rates are seen under AMY (thick and short) and FIL (thickest and shortest), which have larger as- pect ratios than RON (thick and long). ROS (thin and long) has the smallest melt rate.

Using the present-day AMY and RON aspect ratios $\left(\epsilon_{\mathrm{AMY}}, \epsilon_{\mathrm{RON}}\right)$ and associated quadratic laws as reference melt functions $\left(\dot{M} g_{\text {AMY }}, \dot{M} g_{\text {RON }}\right)$, the GLZ melt rate ( $\left.\dot{M g}\right)$ for a shelf of thickness $H$ (in metres) with aspect ratio $\left(\epsilon_{\text {shf }}\right)$ can be computed using $\epsilon_{\text {shf }}$ as a weighting factor and interpolating between the two reference functions.

$$
\begin{aligned}
\dot{\mathrm{Mg}} & =-7.95 \times 10^{-06} H^{2}+8.38 \times 10^{-03} H-2.19 \\
\dot{\mathrm{M}} \mathrm{g}_{\text {RON }} & =-5.10 \times 10^{-06} H^{2}+5.92 \times 10^{-03} H-1.62
\end{aligned}
$$

The ice shelf weighting factor is computed as

$W_{\mathrm{shf}}=\frac{\epsilon_{\mathrm{shf}}-\epsilon_{\mathrm{AMY}}}{\epsilon_{\mathrm{RON}}-\epsilon_{\mathrm{AMY}}}$.

The final GLZ melt rate $\left(\mathrm{m} \mathrm{yr}^{-1}\right)$ is computed from

$\dot{M} g=f n G L z N\left[\dot{M} g_{\text {AMY }}+W_{\text {shf }}\left[\dot{M g}_{\text {RON }}-\dot{M} g_{\text {AMY }}\right]\right]$,

where ensemble parameter fnGLzN allows the strength of the computed melt to be adjusted: SSMGLz1C (range 0.5-3) for the larger shelves and SSMGLz2C (range 0.5-2.5) for the OTHER shelves. The aspect ratio for the OTHER shelves is always set to be the maximum of the large shelves, motivated by the fact that they are closer to the CDW so will likely suffer stronger melt for a given thickness. As the shelves evolve over time, the aspect ratio will also evolve, reducing or increasing the amount of melt proportionally. The calculation of length is computationally costly. As such, it is only performed every $20 \mathrm{yr}$.

The basal accretion $\left(\mathrm{m} \mathrm{yr}^{-1}\right)$ in the $\mathrm{ACZ}$ is modelled using a quadratic function that increases from zero at the two transition zones to a maximum near the centre:

$\dot{\mathrm{Ma}}=-\frac{1}{45000}(H-550)^{2}+0.5$.

The maximum accretion is set to be $0.5 \mathrm{myr}^{-1}$ for all shelves $^{7}$. ACZ accumulation, being a product of the GLZ mode 1 melt, should not exceed $\dot{M g}$. If this does occur, the total $\dot{M}$ a is recomputed to be equal to $\dot{\mathrm{Mg}}$ melt and is redistributed over the ACZ area. For present day this condition only occurs in ROS where, because of the shallow draught, the total GLZ melt is very low. Thus, because of the large area of the ACZ, the redistribution can reduce freeze-on amounts to near $0 \mathrm{~m} \mathrm{yr}^{-1}$ values (see Fig. 3).

The SFZ melt is modelled in accordance with the exponential law presented in Horgan et al. (2011). Within $60 \mathrm{~km}$ of the ice shelf front, the melt $\left(\mathrm{m} \mathrm{yr}^{-1}\right)$ follows the form

$$
\begin{aligned}
\dot{\text { Ms }} & =(1+\mathbf{S S M f r o n t T C} \times(\mathrm{zclim}(t)-1)) \\
& \times 2.0 \exp \left(\frac{-x}{11.9 \mathrm{~km}}\right),
\end{aligned}
$$

\footnotetext{
${ }^{7}$ From the transects and the RON (Joughin and Padman, 2003, Fig. 2) and ROS melt maps (Holland et al., 2003, Fig. 10), the accretion is generally very low $\left[0.5 \mathrm{myr}^{-1}\right]$. Only for AMY does it become significantly higher, with a maximum of $1.5 \mathrm{~m} \mathrm{yr}^{-1}$.
} 
Table 4. Table showing dimensions of the 4 major shelves and the calculated aspect ratio, $\epsilon=[H] /[L]$. Area, average length (see text), and thickness are computed from ALBMAP. Melt rates given in bold are derived estimates (see SSM verification discussion and Supplement Table 4).

\begin{tabular}{lccccccl}
\hline Code & $\begin{array}{c}\text { Area } \\
10^{3} \mathrm{~km}^{2}\end{array}$ & $\begin{array}{c}\text { Average } H \\
\mathrm{~m}\end{array}$ & $\begin{array}{c}\text { Max } H \\
\mathrm{~m}\end{array}$ & $\begin{array}{c}\text { Average } \\
\text { length } \\
\mathrm{km}\end{array}$ & $\begin{array}{c}\text { Average } \\
\text { melt rate } \\
\mathrm{m} \mathrm{yr}^{-1}\end{array}$ & Melt rate estimate source \\
\hline AMY & 57 & 580 & 1508 & 198 & 2.9 & $0.51 \pm 0.13$ & Yu et al. (2010) \\
ROS & 483 & 395 & 783 & 295 & 1.3 & 0.1 & Reddy et al. (2010) \\
RON & 348 & 646 & 1538 & 298 & 2.2 & $\mathbf{0 . 1 9}$ & Joughin and Padman (2003) \\
FIL & 77 & 792 & 1107 & 163 & 4.9 & $\mathbf{0 . 2 5}-0.35$ & Joughin and Padman (2003), \\
other & 459 & 285.57 & 1478 & $\mathrm{n} / \mathrm{a}$ & $\mathrm{n} / \mathrm{a}$ & $\mathrm{n} / \mathrm{a}$ & Grosfeld et al. (1998) \\
\hline
\end{tabular}

where $x$ is distance from the ice shelf front and zclim is the interglacial index factor defined above for the thin ice treatment.

Ensemble parameter SSMfrontC is used to scale $\dot{M}$ s if the region is a large ice shelf. For the smaller shelves, Ms has a fixed factor of 1.5 (in earlier assessments of the GSM, adjustment of the SFZ for the smaller shelves had little impact). In the event of the ACZ grid cells encroaching into the SFZ (ice thickness in the grid cells at the ice shelf front being $>400 \mathrm{~m}$ ) the accretion is set to $0 \mathrm{myr}^{-1}$. We reason that, at the ice shelf front, ISW would be advected away by CDW and/or coastal currents (Jacobs et al., 1992).

The output from the SSM component is presented in Fig. 5, 6, and 3. Figure 5 shows transects and melt maps for AMY ( $a$ and d), RON (b and e), and ROS (c and f). The observed and computed melt rates from the high $\left(\mathrm{H}_{5}\right.$ from $\left.\mathrm{ALBMAP}_{5}\right)$ and low $\left(H_{40}\right.$ from $\left.\mathrm{ALBMAP}_{40}\right)$ resolution thickness transects is shown for AMY and RON. Both $H_{5}$ and $H_{40}$ are presented to compare the effect of the resolution change. All the computed melt rates use SSM ensemble parameters set to unity, thus removing their influence. Given that there are no observations for ROS, only the computed melt rate is shown (i.e. by interpolating between the two references functions using the aspect ratio computed from the estimated length scale and $H_{5}$ thickness).

The melt rate spatial distributions of the major shelves, again calculated using $\mathrm{H}_{5}$ thickness and with the ensemble parameters set to unity, are shown in Fig. 5d-f. The $400 \mathrm{~m}$ and $700 \mathrm{~m}$ zone transition thresholds are shown on the melt maps; the spatial distribution can be compared with the published melt maps for FIL (Fig. 2 of Joughin and Padman, 2003) and ROS (Fig. 10 of Holland et al., 2003). There is no melt map for AMY, but a comparison can be made with the marine-ice thickness map (Fricker et al., 2001, Fig. 3), e.g. to delineate between the GLZ and ACZ.

\section{SSM verification}

To verify the SSM component, we make comparisons with the available observations. Obtaining direct SSM measure- ments is understandably difficult given the environment in which it occurs (Heimbach and Losch, 2012). A variety of techniques, including oceanographic (e.g. Jacobs et al., 1992; Jacobs et al., 1996), geochemical (e.g. Jacobs et al., 1992; Smethie Jr. and Jacobs, 2005; Loose et al., 2009), remote sensing (e.g. Fricker et al., 2001; Joughin and Padman, 2003; Lambrecht et al., 2007), borehole (e.g. Zotikov et al., 1980; Nicholls et al., 1991), and modelling studies (e.g. Holland et al., 2003; Payne et al., 2007) have been employed to obtain SSM volumes, magnitudes, and spatial distributions. The observations, as extracted from the literature, are presented in Supplement Table 3; some processing and conversion were performed to convert the raw data into a dataset that could be used for verification, shown in Supplement Table 4.

The observed and predicted net mass loss for the ice shelf regions are shown in Fig. 6. Five sets of model-derived SSM magnitudes are shown. These include the melt rates computed using the $\mathrm{H}_{5}$ thickness dataset and unity ensemble parameters, and four computed using the GSM initialized with $H_{40}$ and with different parameter settings (no ice dynamic computations were performed, only the ice shelf melt component is executed, to generate the data): upper bound parameters, unity parameters, run nn2679 parameter values and lower bound values.

The unity parameter run removes the influence of the ensemble parameters. Apart from FIL, the modelled total melt is similar to observations. The upper and lower bound runs have all ensemble parameters set to the highest and lowest values respectively as defined in Table 2 and are presented to show the maximum and minimum range the SSM component is capable of. Run nn2679 is the baseline run used in the sensitivity assessment (see Sect. 3). Values from the SSM component bracket observational inferences for AMY, ROS, and, although biased high, RON. The component generates excessive melt for FIL. The higher melt produced by RON and FIL is caused through excess GLZ melt. For the OTHER shelves, the SSM component is at the lower bound of the observations.

The spatial melt map produced by the runs with upper (run 9164) and lower (run 9165) bound parameters are presented 
in Fig. 3. The $H_{40}$ run (with parameters set to unity) melt map is similar to the high-resolution melt map shown in Fig. 5 and is therefore not shown.

\subsection{Spin-up and initialization of the model}

The following factors were considered in determining the GSM initialization procedure. Firstly, a full suite of self consistent boundary conditions (e.g. bedrock elevation and characteristics, ice thickness, internal ice temperature and velocity fields, geothermal heat flux, etc.) must be prescribed for the time at which the GSM is to be initialized. Secondly, the thermodynamical response time of the ice sheet operates on order $100 \mathrm{kyr}$ timescales; the model must be run for at least a glacial cycle for the initial temperature condition, and the associated uncertainties, to be "forgotten" by the ice (Ritz et al., 2001). The time of initialization must account for this. Finally, part of the evaluation methodology to constrain the ensemble of runs produced by this GSM uses Eemian ( $\sim 120 \mathrm{ka}$ ) sea level estimates (Briggs and Tarasov, 2013); thus to meet the second requirement we require a start time that must be at least one glacial cycle prior to the Eemian. To meet these requirements and based on previous ensembles, $205 \mathrm{ka}$ was identified as an appropriate start time to begin each model run (sea level and the modelled AIS volume being close to present day).

Generation of the spin-up configuration was performed as follows. (1) An initial internal ice sheet temperature regime was computed as an equilibrium temperature produced under diffusive heat transport and ALBMAP ice sheet configuration with the surface temperature defined at $391 \mathrm{ka}$ and basal temperature set to $-6^{\circ} \mathrm{C}$. An ad hoc attempt to better account for advection (via proximity to the pressure melting point) while avoiding potential initial numerical instabilities from basal ice at the pressure melting point guided our choice of an initial basal temperature that was proximal to but not at the basal melting point. The initial geothermal temperature profile was also set to equilibrium for the given basal temperature and deep geothermal heat flux as boundary conditions. The $391 \mathrm{ka}$ initial surface temperature was chosen due to it having a Deuterium value which corresponds to the inferred local mean temperature for the 418-205 ka interval (418 ka has a match to present-day Deuterium value and therefore inferred temperature). In other words, the model is equilibrated with the mean surface temperature over a temporal interval that corresponds to the advection timescale of the interior of the AIS (thickness/accumulation rate $=4 \mathrm{~km} / 2 \mathrm{~cm}$ ). (2) An internal velocity configuration is generated by initializing the GSM with ALBMAP assuming isostatic equilibrium and the internal temperature computed in step 1. (3) starting from the above configuration, a small ensemble of 134 runs was generated (the parameter ranges were determined from previous runs) that ran from $391 \mathrm{ka}$ to present day with transient climate forcing and full thermodynamics. The $391 \mathrm{ka}$ initialization temperature field for step (1) retains the usual depen- dence on the ensemble parameters. However, from $391 \mathrm{ka}$ until $200 \mathrm{ka}$ ice dynamics are only active every $25 \mathrm{kyr}$ for a period of just 100 yr. From 200 ka to present, ice dynamics were continuously active. The output of these runs was assessed and the best run (closest to present-day configuration) was used as the starting configuration for the ensemble at $205 \mathrm{ka}$.

\section{Sensitivity study}

In the context of large ensemble analysis, the objective of the sensitivity study is to verify that (a) each parameter has a significant effect ( $\sim 20 \%$ relative to range over all parameters) on at least one characteristic of the model output (e.g. total grounded ice volume) and (b) collectively the parameter ranges provide adequate coverage to bracket the observed values of the ice sheet metrics (characteristics). For computational efficiency, the sensitivity analysis is also used to reduce parameter ranges when extremal values cause numerical instabilities and/or blatantly unacceptable model results (e.g. suppressing WAIS formation).

The appropriate choice of metrics is driven by the scientific question being addressed, in this case the evaluation of a deglaciation chronology, as discussed in Briggs and Tarasov $(2013)^{8}$. For the purposes of this sensitivity study, we use 6 metrics: grounded ice volume (above flotation, in eustatic sea level equivalent, $\mathrm{mESL}^{9}$ ) for present-day WAIS ( vollogw; where volume $=$ vol, present day $=0$, grounded $=\mathrm{g}$, and WAIS $=\mathrm{w}$ ) and for EAIS $(\text { vologe; EAIS }=\mathrm{e})^{10}$, total grounded ice volume for the LGM (vol20g), the zonal position of the present-day Ross Ice Shelf grounding line (ROSgl; ROS $=$ Ross Ice Shelf, $\mathrm{gl}=$ grounding line) along the $81^{\circ} \mathrm{S}$ line of latitude ${ }^{11}$, and the present-day ice shelf areas for ROS and for RON-FIL.

Finding the appropriate range for each parameter is an iterative process. Initially the parameter ranges are set using best guess values, either taken from the literature or from experience gained during the development of the components (e.g. the SSM component). From these initial ranges, sensitivity ensembles are generated, evaluation of which

\footnotetext{
${ }^{8}$ Briggs and Tarasov (2013) present a constraint database of present-day (derived from ALBMAP) and palaeo-data (Eemian volume estimates, relative sea level curves, past ice surface indicators and grounding line retreat data) for Antarctica. They describe a structured method of applying these data to a large ensemble of model runs. The evaluation process they present addresses the uncertainties found in the observational measurements, some of the structural error in the model, and the problems that must be addressed in integrating them together.

${ }^{9}$ Conversion factor of $10^{6} \mathrm{~km}^{3}$ of ice $=2.519 \mathrm{mESL}$.

${ }^{10}$ WAIS and EAIS are separated along a line-arc-line, defined as $30^{\circ} \mathrm{W}-85^{\circ} \mathrm{S}-170^{\circ} \mathrm{W}$.

${ }^{11}$ observed grounding line along the $81^{\circ} \mathrm{S}$ line of latitude (present-day location taken as $81^{\circ} \mathrm{S}, 155^{\circ} \mathrm{W}$ ).
} 
potentially refines the ranges and, if required, might provoke the incorporation of new parameters to provide more degrees of freedom in the model or, conversely, removal of superfluous parameters.

Once the parameters and associated ranges have been verified to achieve the requirements of objectives (a) and (b), there is, ideally, sufficient confidence to justify the computational expenditure required to generate (and evaluate) a full ensemble. Deeper analysis of the full ensemble results can then be used to verify that full coverage has been achieved (within the parameter space created by the 31 parameters).

Sensitivity plots (Figs. 8-10) present the impact each parameter has on the selected metrics. The baseline run (nn2679) is one of the "better" runs as identified through the application of the constraint database and the evaluation methodology presented in Briggs and Tarasov (2013). This control run is slightly biased to excess ice volume (Fig. 8) with $<0.5 \mathrm{mESL}$ difference from the ALBMAP volume. Similarly the ice shelf areas are smaller than that of ALBMAP. But for all metrics, model results for the indicated parameter ranges fully bracket ALBMAP values.

\subsection{Discussion of parameter/metric sensitivity}

Many of the parameters exhibit associated non-linear behaviour in one or more of the metrics. For instance, the impact of increasing the ice shelf pinning parameter (fnpin) on ROS and RON-FIL ice shelf areas is non-monotonic. Furthermore, the impact is qualitatively different for each of the two ice shelf areas.

Over the range of parameters, vologw is more sensitive than vologe $(\sim 9 \mathrm{~m}$ range of variation in comparison to $\sim 5 \mathrm{~m}$ ). Only a few of the parameters cause a large spread (predominately calving and climate parameters). The majority of parameters produce less than $\pm 1 \mathrm{mESL}$ of variation for both metrics. An unexpected result is the lower sensitivity of vologw to the ice shelf flow enhancement parameter compared to that of vologe. However, this was the not case for earlier sensitivity studies (around some other baselines before the large ensemble was complete). Furthermore, if one considers the grounded root mean squared fits to presentday (ALBMAP) ice thickness, then the ice shelf flow parameter has a much bigger impact on WAIS (317 to $352 \mathrm{~m}$ range grounded, and 374 to $414 \mathrm{~m}$ floating) then EAIS (204 to $213 \mathrm{~m}$ grounded). This underscores the necessity of examining a wide range of metrics for sensitivity analyses.

The ice-ocean parameters have more impact on the present-day WAIS rather than EAIS. All but the large ice shelf grounding line zone coefficient SSMGLz1C have less impact during LGM when the ice shelf area was reduced. The ice shelf melt parameters have less impact than the calving parameters, except on the ice shelf area metrics. The grounding line zone melt factor for OTHER ice shelves (SSMGLz2C) has the least impact of any ensemble parameter on the given metrics. It does however have a greater than median impact on the difference in ice volume between $120 \mathrm{ka}$ and present day (Supplement Fig. 7).

The climate forcing parameters have much more impact on vol20g than on vologw and vologe, as many of them only affect past climates, not present day. The climate mixing parameter, Tmix1, is one of the few parameters with a strong influence over all metrics. Tmix1 is the weight between the two climate forcings $\mathrm{Tf}_{1}$ and $\mathrm{Tf}_{2}$, where $\mathrm{Tf}_{1}$ is a fully parameterized climate and $\mathrm{Tf}_{2}$ is based on modern observed climatology (Sect. 2.9.1, Eq. 11). Tmix1 also has a strong impact on the major components of the aggregate score in the Briggs and Tarasov (2013) methodology. For instance the RSL misfit (Supplement Fig. 7) has high sensitivity to Tmix1. Despite this strong influence, the quantitative scores in the Briggs and Tarasov (2013) methodology remain only in mid-ranges as Tmix1 takes on values from 0 to 1 within a large ensemble; i.e. neither a dominant $\mathrm{Tf}_{1}$ nor $\mathrm{Tf}_{2}$ consistently produces better runs. The other climate mixing parameter Tmix2, which weights the third climate forcing $\mathrm{Tf}_{3}$ in Eq. (11), is also influential but to a lesser degree, probably because $\mathrm{Tf}_{3}$ is based on the same modern climatology as $\mathrm{Tf}_{2}$.

\section{Summary and conclusions}

We have modified the PSU 3-D ice sheet model through the inclusion of six climate forcing parameterizations, a basal drag parameterization (accounting for sediment likelihood, topographic roughness, and systematic model to observation thickness misfit), a visco-elastic isostatic adjustment solver, tidewater and ice shelf calving functionality, and a newly developed sub-ice-shelf melt (SSM) component. To perform ensemble analysis, 31 ensemble parameters are used to explore the uncertainty in the ice physics (predominately the definition of the basal drag coefficients), the climate forcing, and the ice-ocean interface.

The SSM component captures the melt-freeze-melt regime of the larger shelves and the simpler regime of the smaller, peripheral, ice shelves. The SSM component produces total melt comparable to published SSM observations for AMY, ROS, and RON, but produces too much melt for FIL. The melt pattern is similar to melt patterns in other published studies. Except for the use of the zclim interglacial index in the ice shelf front melt, the SSM component does not directly account for the spatially or temporally diverse regime of oceanographic forcing. However, as the sub-iceshelf melt law is a function of the aspect ratio of the individual ice shelf, the current SSM implementation does include regional variability in sub-ice-shelf melt regimes. Future studies will examine the impact of marine temperature variations on sub-ice-shelf melt behaviour and associated ice shelf evolution.

Through the sensitivity study we have verified that for the 31 parameters described, each has significant influence over at least one of the 6 model metrics. The sensitivity study also 
highlights the non-linear behaviour of many of the parameters. The model sensitivities to these parameters are a subset of the uncertainties that all glacial cycle models of Antarctic ice sheet evolution either implicitly or explicitly contain.

\section{Supplementary material related to this article is available online at http://www.the-cryosphere.net/7/ 1949/2013/tc-7-1949-2013-supplement.pdf.}

Acknowledgements. The authors would like to thank Mike Bentley for undertaking a critical review of an early version of this work. Two anonymous reviewers and especially a detailed review by Pippa Whitehouse helped improve the clarity of this contribution. This paper is a contribution to the INQUA-sponsored Meltwater Ocean Cryosphere Atmosphere Response (MOCA) network. This work was supported by an NSERC Discovery Grant (LT), the Canadian Foundation for Innovation (LT), and the Atlantic Computational Excellence Network (ACEnet). LT holds a Canada Research Chair.

Edited by: F. Pattyn

\section{References}

Albrecht, T., Martin, M., Haseloff, M., Winkelmann, R., and Levermann, A.: Parameterization for subgrid-scale motion of ice-shelf calving fronts, The Cryosphere, 5, 35-44, doi:10.5194/tc-5-352011, 2011.

Alley, R. B. and Whillans, I. M.: Response of the East Antarctica Ice Sheet to Sea-Level Rise, J. Geophys. Res., 89, 6487-6493, doi:10.1029/JC089iC04p06487, 1984.

Alley, R. B., Horgan, H. J., Joughin, I., Cuffey, K. M., Dupont, T. K., Parizek, B. R., Anandakrishnan, S., and Bassis, J.: A Simple Law for Ice-Shelf Calving, Science, 322, 1344, doi:10.1126/science.1162543, 2008.

Amundson, J. M. and Truffer, M.: A unifying framework for iceberg-calving models, J. Glaciol., 56, 822-830, doi:10.3189/002214310794457173, 2010.

Arthern, R. J., Winebrenner, D. P., and Vaughan, D. G.: Antarctic snow accumulation mapped using polarization of 4.3-cm wavelength microwave emission, J. Geophys. Res., 111, D06107, doi:10.1029/2004JD005667, 2006.

Bamber, J. L., Alley, R. B., and Joughin, I.: Rapid response of modern day ice sheets to external forcing, Earth Planet. Sci. Lett., 257, 1-13, doi:10.1016/j.eps1.2007.03.005, 2007.

Beckmann, A.: A parameterization of ice shelf-ocean interaction for climate models, Ocean Model., 5, 157-170, doi:10.1016/S14635003(02)00019-7, 2003.

Bentley, M. J.: The Antarctic palaeo record and its role in improving predictions of future Antarctic Ice Sheet change, J. Quaternary Sci., 25, 5-18, doi:10.1002/jqs.1287, 2010.

Braconnot, P., Otto-Bliesner, B., Harrison, S., Joussaume, S., Peterchmitt, J.-Y., Abe-Ouchi, A., Crucifix, M., Driesschaert, E., Fichefet, Th., Hewitt, C. D., Kageyama, M., Kitoh, A., Laîné, A., Loutre, M.-F., Marti, O., Merkel, U., Ramstein, G., Valdes,
P., Weber, S. L., Yu, Y., and Zhao, Y.: Results of PMIP2 coupled simulations of the Mid-Holocene and Last Glacial Maximum Part 1: experiments and large-scale features, Clim. Past, 3, 261277, doi:10.5194/cp-3-261-2007, 2007.

Briggs, R. and Tarasov, L.: How to evaluate model derived deglaciation chronologies: A case study using Antarctica, Quaternary Sci. Rev., 63, 109-127, doi:10.1016/j.quascirev.2012.11.021, 2013.

Calov, R., Greve, R., Abe-Ouchi, A., Bueler, E., Huybrechts, P., Johnson, J. V., Pattyn, F., Pollard, D., Ritz, C., Saito, F., and Tarasov, L.: Results from the Ice-Sheet Model Intercomparison Project-Heinrich Event INtercOmparison (ISMIP HEINO), J. Glaciol., 56, 371-383, 2010.

Comiso, J. C.: Variability and Trends in Antarctic Surface Temperatures from In Situ and Satellite Infrared Measurements, J. Climate, 13, 1674-1696, doi:10.1175/15200442(2000)013<1674:VATIAS>2.0.CO;2, 2000.

Cornford, S., Martin, D., Graves, D., Ranken, D., Brocq, A. L., Gladstone, R., Payne, A., Ng, E., and Lipscomb, W. H.: Adaptive mesh, finite volume modeling of marine ice sheets, J. Comput. Phys., 232, 529-549, doi:10.1016/j.bbr.2011.03.031, 2013.

Cuffey, K. and Paterson, W.: The Physics of Glaciers, Academic Press, Butterworth-Heinemann/Elsevier, 2010.

Dinniman, M. S., Klinck, J. M., and Smith, Jr., W. O.: A model study of Circumpolar Deep Water on the West Antarctic Peninsula and Ross Sea continental shelves, Deep-Sea Res. Pt. II, 58, 1508-1523, 2011.

Dupont, T. K. and Alley, R. B.: Assessment of the importance of ice-shelf buttressing to ice-sheet flow, Geophys. Res. Lett., 32, L04503, doi:10.1029/2004GL022024, 2005.

Fox Maule, C., Purucker, M. E., Olsen, N., and Mosegaard, K.: Heat flux anomalies in Antarctica revealed by satellite magnetic data., Science, 309, 464-467, doi:10.1126/science.1106888, 2005.

Fricker, H. A., Popov, S., Allison, I., and Young, N.: Distribution of marine ice beneath the Amery Ice Shelf, Geophys. Res. Lett., 28, 2241-2244, 2001

Grosfeld, K., Hellmer, H., Jonas, M., Sandhäger, H., Schulte, M., and Vaughan, D.: Marine ice beneath Filchner Ice Shelf Evidence from a multi-disciplinary approach, in: Ocean, ice and atmosphere Interactions at the Antarctic continental margin, edited by: Jacobs, S. and Weiss, R., vol. 75 of Antarct. Res. Ser., 319339, AGU, Washington DC, 1998.

Heimbach, P. and Losch, M.: Adjoint sensitivities of sub-iceshelf melt rates to ocean circulation under the Pine Island Ice Shelf, West Antarctica, Ann. Glaciol., 53, 59-69, doi:10.3189/2012/AoG60A025, 2012.

Holland, D. M., Jacobs, S. S., and Jenkins, A.: Modelling the ocean circulation beneath the Ross Ice Shelf, Antarct. Sci., 15, 13-23, doi:10.1017/S0954102003001019, 2003.

Holland, P. R., Jenkins, A., and Holland, D. M.: The Response of Ice Shelf Basal Melting to Variations in Ocean Temperature, J. Climate, 21, 2558, doi:10.1175/2007JCLI1909.1, 2008.

Horgan, H., Walker, R., Anandakrishnan, S., and Alley, R.: Surface elevation changes at the front of the Ross Ice Shelf: Implications for basal melting, J. Geophys. Res.-Oceans, 116, C02005, doi:10.1029/2010JC006192, 2011.

Huybrechts, P.: The Antartic ice sheet and enviromental change: a three-dimensional modelling study, Ph.D. thesis, Alfred Wegener Institute for Polar and Marine Research, 1991. 
Huybrechts, P.: Sea-level changes at the LGM from ice-dynamic reconstructions of the Greenland and Antarctic ice sheets during the glacial cycles, Quaternary Sci. Rev., 21, 203-231, doi:10.1016/S0277-3791(01)00082-8, 2002.

Huybrechts, P.: Antarctica: modelling, in: Mass balance of the cryosphere: observations and modelling of contemporary and future changes, edited by: Bamber, J. and Payne, A., 491-523, Cambridge, Cambridge University Press, 2004.

Huybrechts, P., Abe-Ouchi, A., Marsiat, I., Pattyn, F., Payne, T., Ritz, C., and Rommelaere, V.: Report of the third EISMINT workshop on model intercomparison, European Science Foundation (Strasbourg), 1998.

Jacobs, S., Hellmer, H. H., Doake, C. S. M., Jenkins, A., and Frolich, R.: Melting of ice shelves and the mass balance of Antarctica, J. Glaciol., 38, 375-387, 1992.

Jacobs, S., Hellmer, H., and Jenkins, A.: Antarctic ice sheet melting in the Southeast Pacific, Geophys. Res. Lett., 23, 957-960, doi:10.1029/96GL00723, 1996.

Jenkins, A. and Doake, C. S. M.: Ice-ocean interaction on Ronne Ice Shelf, Antarctica, J. Geophys. Res., 96, 791-813, doi:10.1029/90JC01952, 1991.

Jenkins, A., Dutrieux, P., Jacobs, S. S., McPhail, S. D., Perrett, J. R., Webb, A. T., and White, D.: Observations beneath Pine Island Glacier in West Antarctica and implications for its retreat, Nature, 3, 468-472, 2010.

Joughin, I. and Padman, L.: Melting and freezing beneath FilchnerRonne Ice Shelf, Antarctica, Geophys. Res. Lett., 30, 1477, doi:10.1029/2003GL016941, 2003.

Jouzel, J. and Masson-Delmotte, V.: EPICA Dome C Ice Core 800KYr Deuterium Data and Temperature Estimates, IGBP PAGES/World Data Center for Paleoclimatology Data Contribution Series, 2007-091, 2007.

Lambrecht, A., Sandhäger, H., Vaughan, D., and Mayer, C.: New ice thickness maps of Filchner-Ronne Ice Shelf, Antarctica, with specific focus on grounding lines and marine ice, Antarct. Sci., 19, 521-532, doi:10.1017/S0954102007000661, 2007.

Laskar, J., Robutel, P., Joutel, F., Gastineau, M., Correia, A. C. M., and Levrard, B.: A long-term numerical solution for the insolation quantities of the Earth, Astron. Astrophys., 428, 261-285, 2004.

Le Brocq, A. M., Payne, A. J., and Vieli, A.: An improved Antarctic dataset for high resolution numerical ice sheet models (ALBMAP v1), Earth Syst. Sci. Data, 2, 247-260, doi:10.5194/essd-2-247-2010, 2010.

Lisiecki, L. E.: A Pliocene-Pleistocene stack of 57 globally distributed benthic $\delta^{18} \mathrm{O}$ records, Paleoceanography, 20, PA1003, doi:10.1029/2004PA001071, 2005.

Loose, B., Schlosser, P., Smethie, W. M., and Jacobs, S.: An optimized estimate of glacial melt from the Ross Ice Shelf using noble gases, stable isotopes, and CFC transient tracers, J. Geophys. Res.-Oceans, 114, 8007, doi:10.1029/2008JC005048, 2009.

Ma, Y., Gagliardini, O., Ritz, C., Gillet-Chaulet, F., Durand, G., and Montagnat, M.: Enhancement factors for grounded ice and ice shelves inferred from an anisotropic ice-flow model, J. Glaciol., 56, 805-812, doi:10.3189/002214310794457209, 2010.

MacAyeal, D. R.: EISMINT: Lessons in Ice-Sheet Modeling, 1997.

Marshall, S. J., James, T. S., and Clarke, G. K. C.: North American Ice Sheet reconstructions at the Last Glacial Maximum, Quaternary Sci. Rev., 21, 175-192, 2002.
Martin, M. A., Winkelmann, R., Haseloff, M., Albrecht, T., Bueler, E., Khroulev, C., and Levermann, A.: The Potsdam Parallel Ice Sheet Model (PISM-PIK) - Part 2: Dynamic equilibrium simulation of the Antarctic ice sheet, The Cryosphere, 5, 727-740, doi:10.5194/tc-5-727-2011, 2011.

Meehl, G., Stocker, T., Collins, W., Friedlingstein, P., Gaye, A., Gregory, J., Kitoh, A., Knutti, R., Murphy, J., Noda, A., Raper, S., Watterson, I., Weaver, A., and Zhao, Z.-C.: Climate Change 2007: The Physical Basis: Contributions of Working Group 1 to the Fourth Assessment Report of the Intergovernmental Panel on Climate Change, chap. 10, Cambridge University Press Cambridge, New York, Melbourne, Madrid, Cape Town, Singapore, São Paulo, Delhi, 2007.

Mercer, J. H.: West Antarctic ice sheet and $\mathrm{CO}_{2}$ greenhouse effect: a threat of disaster, Nature, 271, 321-325, doi:10.1038/271321a0, 1978.

Neal, C. S.: The dynamics of the Ross Ice Shelf revealed by radio echo-sounding, J. Glaciol., 24, 295-307, 1979.

Nicholls, K. W., Makinson, K., and Robinson, A. V.: Ocean circulation beneath the Ronne ice shelf, Nature, 354, 221-223, doi:10.1038/354221a0, 1991.

Nicholls, K. W., Østerhus, S., Makinson, K., Gammelsrød, T., and Fahrbach, E.: Ice-ocean processes over the continental shelf of the southern Weddell Sea, Antarctica: A review, Rev. Geophys., 47, RG3003, doi:10.1029/2007RG000250, 2009.

Olbers, D. and Hellmer, H.: A box model of circulation and melting in ice shelf caverns, Ocean Dynam., 60, 141-153, doi:10.1007/s10236-009-0252-z, 2010.

Pattyn, F.: Antarctic subglacial conditions inferred from a hybrid ice sheet/ice stream model, Earth Planet. Sci. Lett., 295, 451-461, doi:10.1016/j.epsl.2010.04.025, 2010.

Pattyn, F., Perichon, L., Aschwanden, A., Breuer, B., de Smedt, B., Gagliardini, O., Gudmundsson, G. H., Hindmarsh, R. C. A., Hubbard, A., Johnson, J. V., Kleiner, T., Konovalov, Y., Martin, C., Payne, A. J., Pollard, D., Price, S., Rückamp, M., Saito, F., Souček, O., Sugiyama, S., and Zwinger, T.: Benchmark experiments for higher-order and full-Stokes ice sheet models (ISMIPHOM), The Cryosphere, 2, 95-108, doi:10.5194/tc-2-95-2008, 2008.

Pattyn, F., Schoof, C., Perichon, L., Hindmarsh, R. C. A., Bueler, E., de Fleurian, B., Durand, G., Gagliardini, O., Gladstone, R., Goldberg, D., Gudmundsson, G. H., Huybrechts, P., Lee, V., Nick, F. M., Payne, A. J., Pollard, D., Rybak, O., Saito, F., and Vieli, A.: Results of the Marine Ice Sheet Model Intercomparison Project, MISMIP, The Cryosphere, 6, 573-588, doi:10.5194/tc6-573-2012, 2012.

Payne, A. J., Vieli, A., Shepherd, A. P., Wingham, D. J., and Rignot, E.: Recent dramatic thinning of largest West Antarctic ice stream triggered by oceans, Geophys. Res. Lett., 31, L23401, doi:10.1029/2004GL021284, 2004.

Payne, A. J., Holland, P. R., Shepherd, A. P., Rutt, I. C., Jenkins, A., and Joughin, I.: Numerical modeling of ocean-ice interactions under Pine Island Bay's ice shelf, J. Geophys. Res.-Oceans, 112, C10019, doi:10.1029/2006JC003733, 2007.

Peltier, W. R. and Drummond, R.: Rheological stratification of the lithosphere: A direct inference based upon the geodetically observed pattern of the glacial isostatic adjustment of the North American continent, Geophys. Res. Lett., 35, L16314, doi:10.1029/2008GL034586, 2008. 
Pollard, D. and DeConto, R. M.: A Coupled Ice-Sheet/IceShelf/Sediment Model Applied to a Marine-Margin Flowline: Forced and Unforced Variations, Special Publication International Association of Sedimentologists, 39, 37-52, 2007.

Pollard, D. and DeConto, R. M.: Modelling West Antarctic ice sheet growth and collapse through the past five million years, Nature, 458, 329-332, doi:10.1038/nature07809, 2009.

Pollard, D. and DeConto, R. M.: Modelling West Antarctic ice sheet growth and collapse through the past five million yearsSupplementry, Nature, 458, 329-32, 2009.

Pollard, D. and DeConto, R. M.: A simple inverse method for the distribution of basal sliding coefficients under ice sheets, applied to Antarctica, The Cryosphere, 6, 953-971, doi:10.5194/tcd-61405-2012, 2012a.

Pollard, D. and DeConto, R. M.: Description of a hybrid ice sheetshelf model, and application to Antarctica, Geosci. Model Dev., 5, 1273-1295, doi:10.5194/gmd-5-1273-2012, 2012b.

Pritchard, H. D., Ligtenberg, S. R. M., Fricker, H. A., Vaughan, D. G., van den Broeke, M. R., and Padman, L.: Antarctic icesheet loss driven by basal melting of ice shelves, Nature, 484, 502-505, doi:10.1038/nature10968, 2012.

Reddy, T. E., Holland, D. M., and Arrigo, K. R.: Ross ice shelf cavity circulation, residence time, and melting: Results from a model of oceanic chlorofluorocarbons, Cont. Shelf Res., 30, 733-742, doi:10.1016/j.csr.2010.01.007, 2010.

Rignot, E. and Jacobs, S. S.: Rapid Bottom Melting Widespread near Antarctic Ice Sheet Grounding Lines, Science, 296, 20202023, doi:10.1126/science.1070942, 2002.

Rignot, E., Bamber, J. L., van den Broeke, M. R., Davis, C., Li, Y., van de Berg, W. J., and van Meijgaard, E.: Recent Antarctic ice mass loss from radar interferometry and regional climate modelling, Nat. Geosci., 1, 106-110, doi:10.1038/ngeo102, 2008.

Ritz, C., Rommelaere, V., and Dumas, C.: Modeling the evolution of Antarctic ice sheet over the last 420,000 years: implications for altitude changes in the Vostok region, J. Geophys. Res.-Atmos., 106, 31943-31964, 2001.

Sanderson, T.: Equilibrium profile of ice shelves, J. Glaciol., 22, 435-460, 1979.

Schoof, C.: Ice sheet grounding line dynamics: Steady states, stability, and hysteresis, J. Geophys. Res., 112, F03S28, doi:10.1029/2006JF000664, 2007.

Schoof, C.: Marine ice-sheet dynamics. Part 1. The case of rapid sliding, J. Fluid Mech., 573, 27-55, doi:10.1017/S0022112006003570, 2007.

Shapiro, N. M. and Ritzwoller, M. H.: Inferring surface heat flux distributions guided by a global seismic model: particular application to Antarctica, Earth Planet. Sci. Lett., 223, 213-224, 2004.
Smethie Jr., W. and Jacobs, S.: Circulation and melting under the Ross Ice Shelf: estimates from evolving CFC, salinity and temperature fields in the Ross Sea, Deep-Sea Res. Pt. II, 52, 959978, doi:10.1016/j.dsr.2004.11.016, 2005.

Tarasov, L. and Peltier, W. R.: Greenland glacial history, borehole constraints and Eemian extent, Geophys. Res. Lett., 108, 21242143, 2003.

Tarasov, L. and Peltier, W. R.: A geophysically constrained large ensemble analysis of the deglacial history of the North American ice sheet complex, Quaternary Sci. Rev., 23, 359-388, 2004.

Tarasov, L. and Peltier, W. R.: A calibrated deglacial drainage chronology for the North American continent: Evidence of an Arctic trigger for the Younger Dryas, Quaternary Sci. Rev., 25, 659-688, doi:10.1016/j.quascirev.2005.12.006, 2006.

Tarasov, L., Dyke, A. S., Neal, R. M., and Peltier, W. R.: A data-calibrated distribution of deglacial chronologies for the North American ice complex from glaciological modeling, Earth Planet. Sci. Lett., 315, 30-40, doi:10.1016/j.eps1.2011.09.010, 2012.

Thyssen, F., Bombosch, A., and Sandhäger, H.: Elevation, ice thickness and structure mark maps of the central part of the FilchnerRonne Ice Shelf, Polarforschung, 62, 17-26, 1993.

Van der Veen, C. J.: Calving glaciers, Prog. Phys. Geog., 26, 96122, 2002.

Walker, R. T., Dupont, T. K., Parizek, B. R., and Alley, R. B.: Effects of basal-melting distribution on the retreat of ice-shelf grounding lines, Geophys. Res. Lett., 35, L17503, doi:10.1029/2008GL034947, 2008.

Wen, J., Jezek, K. C., ó, B. M. C., Herzfeld, U. C., Farness, K. L., and Huybrechts, P.: Mass budgets of the Lambert, Mellor and Fisher Glaciers and basal fluxes beneath their flowbands on Amery Ice Shelf, Sci. China Ser. D, 50, 1693-1706, doi:10.1007/s11430-007-0120-y, 2007.

Whitehouse, P. L., Bentley, M. J., and Brocq, A. M. L.: A deglacial model for Antarctica: geological constraints and glaciological modelling as a basis for a new model of Antarctic glacial isostatic adjustment, Quaternary Sci. Rev., 32, 1-24, doi:10.1016/j.quascirev.2011.11.016, 2012.

Yu, J., Liu, H., Jezek, K. C., Warner, R. C., and Wen, J.: Analysis of velocity field, mass balance, and basal melt of the Lambert Glacier-Amery Ice Shelf system by incorporating Radarsat SAR interferometry and ICESat laser altimetry measurements, J. Geophys. Res.-Sol. Ea., 115, B11102, doi:10.1029/2010JB007456, 2010.

Zotikov, I. A., Zagorodnov, V. S., and Raikovsky, J. V.: Core Drilling through the Ross Ice Shelf (Antarctica) Confirmed Basal Freezing, Science, 207, 1463-1465, doi:10.1126/science.207.4438.1463, 1980.

Zwally, H. J. and Fiegles, S.: Extent and duration of Antarctic surface melting, J. Glaciol., 40, 463-476, 1994. 